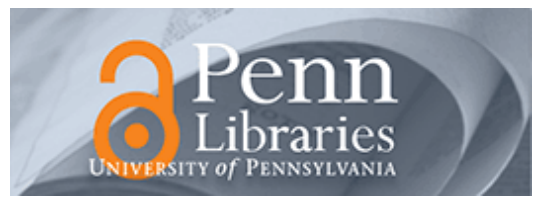

University of Pennsylvania

ScholarlyCommons

\title{
Value Creation in Innovation Ecosystems: How the Structure of Technological Interdependence Affects Firm Performance in New Technology Generations
}

Ron Adner

University of Pennsylvania

Rahul Kapoor

University of Pennsylvania

Follow this and additional works at: https://repository.upenn.edu/mgmt_papers

Part of the Business Administration, Management, and Operations Commons

\section{Recommended Citation}

Adner, R., \& Kapoor, R. (2010). Value Creation in Innovation Ecosystems: How the Structure of Technological Interdependence Affects Firm Performance in New Technology Generations. Strategic Management Journal, 31 (3), 306-333. http://dx.doi.org/10.1002/smj.821

This paper is posted at ScholarlyCommons. https://repository.upenn.edu/mgmt_papers/44

For more information, please contact repository@pobox.upenn.edu. 


\title{
Value Creation in Innovation Ecosystems: How the Structure of Technological Interdependence Affects Firm Performance in New Technology Generations
}

\begin{abstract}
The success of an innovating firm often depends on the efforts of other innovators in its environment. How do the challenges faced by external innovators affect the focal firm's outcomes? To address this question we first characterize the external environment according to the structure of interdependence. We follow the flow of inputs and outputs in the ecosystem to distinguish between upstream components that are bundled by the focal firm, and downstream complements that are bundled by the firm's customers.

We hypothesize that the effects of external innovation challenges depend not only on their magnitude, but also on their location in the ecosystem relative to the focal firm. We identify a key asymmetry that results from the location of challenges relative to a focal firm-greater upstream innovation challenges in components enhance the benefits that accrue to technology leaders, while greater downstream innovation challenges in complements erode these benefits. We further propose that the effectiveness of vertical integration as a strategy to manage ecosystem interdependence increases over the course of the technology life cycle. We explore these arguments in the context of the global semiconductor lithography equipment industry from its emergence in 1962 to 2005 across nine distinct technology generations. We find strong empirical support for our framework.
\end{abstract}

\section{Keywords}

technological change, first mover advantage, business ecosystem, vertical integration, complements, semiconductor lithography

\section{Disciplines}

Business Administration, Management, and Operations 


\title{
Value Creation in Innovation Ecosystems: How the Structure of Technological
}

\section{Interdependence Affects Firm Performance in New Technology Generations}

\author{
Ron Adner \\ Tuck School of Business, Dartmouth College \\ Strategy and Management 100 Tuck Hall \\ Hanover, NH 03755, USA \\ Tel: 16036469185 \\ Email: ron.adner@dartmouth.edu
}

\author{
Rahul Kapoor \\ Wharton School of Business, University of Pennsylvania \\ 3620 Locust Walk, Suite 3025 \\ Philadelphia, PA 19104 \\ Tel: 215-898-6458 \\ Email: kapoorr@wharton.upenn.edu
}

\section{December, 2008}

\begin{abstract}
The success of an innovating firm often depends on the efforts of other innovators in its environment. How do the challenges faced by external innovators affect the focal firm's outcomes? To address this question we first characterize the external environment according to the structure of interdependence. We follow the flow of inputs and outputs in the ecosystem to distinguish between upstream components that are bundled by the focal firm, and downstream complements that are bundled by the firm's customers. We argue that the effect of external innovation challenges depends not only on their magnitude, but also on their location in the ecosystem relative to the focal firm - whereas greater innovation challenges in components enhances the benefits that accrue to technology leaders, greater innovation challenges in complements erodes these benefits. We further argue that the effectiveness of vertical integration as a strategy to manage ecosystem interdependence increases over the course of the technology life cycle. We explore these arguments in the context of the global semiconductor lithography industry from its emergence in 1962 to 2005 across nine distinct technology generations. We find strong support for our arguments.
\end{abstract}

We thank Phil Anderson, Ramon Casadesus-Masanell, Charles Galunic, Martin Gargiulo, Javier Gimeno, Rebecca Henderson, Dan Levinthal, Bill Lazonick, Alessandro Lomi, Marwan Sinaceur, Jasjit Singh, Olav Sorenson, Peter Zemsky and seminar participants at Dartmouth, Duke, Harvard and NYU for their helpful reactions. We especially thank VLSI Research and Rebecca Henderson for their generosity in sharing their data with us. 


\section{INTRODUCTION}

A firm's competitive advantage depends on its ability to create more value than its rivals (Porter, 1996; Brandenburger and Stuart, 1996). Greater value creation, in turn depends on the firms' ability to innovate successfully. To capture the returns from innovation, many firms strive to be technology leaders in their industry by being first to introduce new innovations to the market. A given innovation, however, often does not stand alone; rather, it depends on accompanying changes in the firm's environment for its own success (Adner, 2006). These external changes, which require innovation on the part of other actors, embed the focal firm within an ecosystem of interdependent innovations.

Consider, for example, Airbus's monumental investment in pioneering the super-jumbo passenger aircraft with its A380 offer. Airbus, as the focal firm, faces significant challenges in designing and manufacturing the core airframe of the airplane. Beyond this internal challenge, it also relies on a host of suppliers for subassemblies and components. Some of these suppliers are themselves confronted with significant innovation challenges to deliver components that meet Airbus's requirements (e.g., engine; navigation system), while others will not need to innovate at all (e.g., carpeting). Receiving these various components, Airbus faces the additional challenge of integrating them with the airframe in order to deliver a functioning aircraft to its airline customers. In order for the aircraft to be used productively by airlines, however, a number of other actors in the environment, outside of Airbus's direct supply chain, confront additional innovation challenges as well. Complementors such as airports need to invest and develop new infrastructure to accommodate the oversized aircraft; regulators need to specify new safety procedures; training simulator manufacturers need to develop new simulators on which aircraft crews can be trained. The A380 innovation ecosystem is thus comprised not only of Airbus as 
the core innovator, but also its upstream suppliers, and its downstream buyers and complementors, all of whom need to resolve their own innovation challenges in order for the focal A380 offer to create value.

Understanding competitive advantage in such 'innovation ecosystems,' requires a change in the way in which the strategy field has traditionally approached the relationship between a firm and its external partners. Specifically, it requires an approach that extends beyond the focus on how different actors will bargain over value capture (e.g., Porter, 1980; Brandenburger and Stuart, 1996) to include an explicit consideration of the innovation challenges that different actors will need to overcome in order for value to be created in the first place. In this paper we present an approach to analyzing the dynamics of value creation that focuses on the role of innovation challenges in a firm's ecosystem as potential bottlenecks to value creation. We draw key distinctions between challenges that need to be confronted by the focal firm, its suppliers, and its complementors, and reveal differences in their impact on the firm's ability to create value, as well as their implication for the firm's ability to capture value.

The ecosystem construct, as a way of making interdependencies more explicit, has gained prominence in both business strategy (Moore, 1996; Iansiti and Levien, 2004; Adner, 2006) and practice (e.g., Intel, 2004; SAP, 2006). These approaches have focused on understanding coordination among partners in exchange networks that are characterized by simultaneous cooperation and competition (Brandenburger and Nalebuff, 1997; Afuah, 2000). Studies in this vein explore the challenges that arise when incentives across the ecosystem are not aligned (Casadesus-Masanell and Yoffie, 2005), the role of established relationships with ecosystem partners in shaping firm's motivations to compete for different market segments (Christensen and 
Rosenbloom, 1995), and the activities that focal firms undertake to induce partners to favor their specific technology platforms (Gawer and Cusumano, 2002).

Notice, however, that these studies are primarily concerned with strategic interactions among firms, extending the concerns of bargaining power and leverage from the context of bilateral partnerships (e.g., Teece, 1986) and industries (e.g., Porter, 1980) to the context of ecosystems. Notice too, that while they are clearly sensitive to the presence of different roles and actors along the value chain (i.e., drawing clear distinctions between suppliers, complementors, and buyers), the specific value chain position of a counterparty relative to the focal firm has had no impact on the resulting analysis - i.e., the impact of a partner with high bargaining power on the focal firm's ability to capture value is exactly the same regardless of whether the counter party is positioned as a complementor, a buyer, or a supplier.

In this paper we argue that understanding the dynamics of value creation requires an explicit consideration of the asymmetries that arise from the positions of different counterparties relative to the focal firm. We show a firm's ability to create value is impacted in very different ways depending on whether it is upstream or downstream partners that face innovation challenges - i.e., the impact of high external innovation challenges on the focal firm depends on whether the challenges are confronted by suppliers (which affects the components that the firm needs to integrate in order to offer a complete product to its customers) or by complementors (in which case the firm can offer its complete product to the customer, but the customer cannot utilize it to its full potential).

We examine how the magnitude and the location of innovation challenges within a firm's ecosystem impact its ability to create value and to achieve competitive advantage. We present a simple structure for locating challenges relative to the firm according to the flow of activities 
within the ecosystem. We use this lens to consider two interrelated questions: First, how the structure of technological interdependence - the location of challenges relative to the focal firm affects the benefit that accrues to technology leaders (i.e., firms that pioneer the introduction of new technology generations). Second, how the effectiveness of vertical integration as a strategy for managing technological interdependence changes over the course of a technology's life cycle.

The first mover advantage literature has identified important considerations under which technology leaders gain or lose from early entry into new markets. Both the applied and scholarly literatures are replete with studies, prescriptions, and caveats regarding the merits of pioneering new opportunities (e.g., Leiberman and Montgomery, 1988; 1998; Mitchell, 1991; Golder and Tellis, 1993; Christensen et.al., 1998). Consistent with strong arguments for and against the benefits of leading in the introduction of new innovations, the empirical findings have been decidedly mixed, with some studies reporting significant pioneering advantages, while others report disadvantages and non-effects (e.g., Kerin et.al., 1992; VanderWerf and Mahon, 1997).

The debates over technology leadership have tended to overlook the nature of the technology challenges that leaders and their ecosystems must overcome. In so doing, they have neglected a key contingency. In this paper we move beyond the literature's traditional analysis of firms' positions vis-à-vis their rivals. We explicitly consider the innovation challenges that reside in the firm's environment and need to be confronted by external partners if the focal innovation is to succeed in the market. We develop a simple framework for characterizing the technological uncertainty associated with external innovation challenges. We argue that the location of challenges impacts the steepness of firms' learning curves, their rate of progress along these curves, and the extent of spillovers to rivals. We predict that challenges in components increase 
the performance advantage attributable to technology leaders, while challenges in complements decrease this advantage. ${ }^{1}$ Although external innovation challenges have long been a feature of the technology literature (e.g., Rosenberg, 1976), component and complement challenges have most often been considered simultaneously, and aggregated into the broad category of systems of innovation (e.g., Hughes, 1982). In contrast, by being explicit about the structure of technology interdependence, we distinguish between the roles of component and complements as elements of the ecosystem. To our knowledge, this is the first paper to explicitly postulate and test their asymmetric effects.

In exploring how ecosystem challenges impact innovators' outcomes, an obvious question that arises is how firms can improve their coordination of technological changes within the ecosystem. We consider firms' vertical integration of key components as a governance strategy to manage this interdependence. We integrate arguments from the literatures on technology life cycles (Rosenberg, 1976; Sahal, 1981; Dosi, 1982) and transaction cost economics (Williamson, 1985) and suggest that while technological challenges tend to decrease as technologies mature, contractual challenges need not dissipate over time. Because vertical integration mitigates contractual hazards, but not necessarily technology challenges, we argue that the shifting balance of technological and contractual challenges will act to increase the benefit from vertical integration over the course of the technology life cycle. Hence, vertical integration is likely to be more effective after a technology has reached a stage of maturity, rather than during its emergence.

\footnotetext{
${ }^{1}$ Note that our focus is not in specifying whether technology leaders will have a competitive advantage. Rather, our focus is on specifying whether competitive advantage from technology leadership is enhanced or eroded by the magnitude and location of external innovation challenges.
} 
We test these arguments in the context of the global semiconductor lithography equipment industry from its emergence in 1962 to 2005 , a period during which the industry transitioned through nine distinct technology generations. While focal innovators faced significant challenges in each of these generational transitions, the extent to which suppliers and complementors faced innovation challenges varied across these generations, providing us with an ideal setting in which to test the impact of ecosystem uncertainty on technology leaders. We constructed a unique data set to test our arguments. The data includes a novel measure of ecosystem challenges for each of the nine technology generations, as well as information about every firm that ever participated in the industry.

Our study makes a number of contributions. First, it introduces a structured approach for analyzing technology interdependence. This approach offers a new perspective for understanding innovators' outcomes during periods of technological change (e.g., Tushman and Anderson, 1986). By using an ecosystem lens to examine the benefits of technology leadership, we expand the scope of inquiry beyond its traditional focus on direct competitors to identify the underlying mechanisms by which uncertainty in components and complements exercise opposing effects on the performance of technology leaders and laggards (e.g., Lieberman and Montgomery, 1988). By disaggregating the external environment into upstream and downstream constituents, we show that the location of uncertainty matters no less than its magnitude, and offer a finer grained view of the interaction between organizations and their environments (e.g., Lawrence and Lorch, 1967) and its implication for the dynamics of value creation (e.g. Brandenburger and Stuart, 1996; Adner and Zemsky, 2006); To the best of our knowledge, ours is the first study that operationalizes the environment in this way. By linking the flow of activities among partners to the distribution of innovation challenges across the ecosystem we shed light on a key mechanism 
of joint value creation and contribute to the emerging literature on ecosystem strategy (e.g., Moore, 1996; Iansiti and Levien, 2004; Adner, 2006). Finally, by explicitly considering the changing benefits of vertical integration over the course of the technology lifecycle we contribute towards an understanding of how firm's boundary choices affect their performance outcomes over time (e.g., Stigler, 1951; Argyres and Bigelow, 2007; Novak and Stern, 2008).

\section{AN ECOSYSTEM PERSPECTIVE}

Individual innovations often reside within broader systems. In such cases, understanding an innovation's consequences requires understanding its relationship to its external context. Hughes' (1983) rich description of the emergence of the electrical power network highlights the obstacles raised when some technological elements of an ecosystem lag behind others in resolving their challenges. He attributes the decline of direct current (DC) generation technologies to bottlenecks in the development of distribution technology for the DC network. Conversely, Henderson's (1995) study of the semiconductor lithography industry (the same industry we examine in this paper) highlights the role that suppliers, customers and complementors played in offsetting bottlenecks in optics technology, thereby extending the dominance of optical lithography over non-optical approaches.

While prior studies have highlighted the importance of external innovations to the success of focal initiatives, they have not given a clear structure in which to assess the impact of these external challenges. $^{2}$ In the absence of such structure, the literature's characterization of uncertainty in the external environment has tended remained at an aggregated level - e.g.,

\footnotetext{
2 An exception are Afuah's studies (Afuah, 2000, Afuah and Bahram, 1995) which have explored how firm performance is impacted when partners face technology challenges. These studies focus on the overall level of innovation challenges that partners must confront. In contrast, our study explicitly considers the impact of variations in both the level and the location of challenges within the ecosystem. In so doing, we are able to uncover new insights regarding the asymmetric impact of upstream and downstream uncertainty on innovator's outcomes.
} 
distinguishing between stable vs. variable (Lawrence and Lorsch, 1967); low vs. high velocity (Eisenhardt, 1989); smooth vs. abrupt development (Suarez and Lanzolla, 2007). Although these aggregate characterizations have yielded important insights, we believe that a finer grained level of analysis can offer addition insight still.

Our specific focus is on uncertainty regarding technological innovations. Rather than characterizing the extent of uncertainty in the aggregate, we consider the distribution of innovation challenges across different roles in the ecosystem. We identify these roles and positions by following the flows of inputs and outputs across the external environment.

Figure 1 shows the schema of our approach. The outputs of upstream suppliers serve as inputs to the focal actor. We refer to such inputs, which are bundled by the focal actor, as components. The focal actor's output serves as an input to its customer. A customer may need to bundle the outputs of other firms alongside the focal actor's output to utilize the focal actor's offer. We refer to such inputs, which are bundled by the customer, as complements. In this simple schema, as in our study, we examine only first-tier components and complements; clearly, this structure can be extended forward and backward along the activity chain to include higher tiered actors (e.g., supplier's suppliers; customer's customers). ${ }^{3}$

(Insert Figure 1 about here)

This framework offers a structure in which to analyze the nature of technology interdependence. Tracing the flow of activities in an ecosystem allows for the simultaneous

\footnotetext{
${ }^{3}$ Note that components and complements are defined according to where elements are bundled in the flow of activites relative to the position of the focal offer, not according to whether they are produced by a given firm or outsourced to another. For example, although Hewlett Packard produces both personal computers and printers, they remain separate offers that are brought together by the customer: the printer is a complement to the computer independently of whether it is offered by Hewlett Packard or Cannon.
} 
consideration of a firm's direct interdependence with its suppliers as well as indirect interdependence with its complementors. This structure allows us to disaggregate the broad construct of environmental uncertainty to identify both the location and the magnitude of challenges that surrounds the focal innovator.

\section{TECHNOLOGICAL INTERDEPENDENCE AND FIRM PERFORMANCE}

How do the magnitude and location of technology challenges in the ecosystem affect the benefits of technology leadership? Being first to introduce an improved technology to the market is a common managerial aspiration. Successful technology leaders, by virtue of having beaten their rivals to market, enjoy reduced competition when presenting their offer to customers. Whether this temporary exclusivity translates into a sustained competitive advantage over later entrants, however, depends on the leader's ability to exploit its window of opportunity. This will depend on the relative distribution of challenges across components and complements.

\section{Component Challenges}

New innovations are often enabled by changes in components. In such cases, both firms and their suppliers may face considerable challenges in developing and integrating these new components into the focal offer (Fine, 1998; Brusoni et.al. 2001). How do component challenges affect the performance of technology leaders who pioneer new technology generations?

A key driver of early mover advantage is the opportunity to exploit production and market experience to progress down the learning curve, increasing the firm's added value by improving the offer's performance or costs (e.g., Spence, 1981; Lieberman, 1989; 1984; Argote, 1999). 
Empirical studies of learning curves, from the 1930s to the present day, have found significant variance in learning potential. For example, in their review of twenty two learning curve studies, Dutton and Thomas (1984) report progress ratios that vary from 55\% (high learning opportunity) to over $100 \%$ (no learning opportunity). ${ }^{4}$

The extent to which progress down the learning curve can be a source of advantage is intimately linked to the potential for learning - greater advantage is rooted in greater learning potential. Hence, to understand learning as a source of advantage we must consider what drives differences in the magnitude of the learning opportunity.

The magnitude of the learning opportunity depends on the extent to which the innovating firm needs to change its current approach to problem solving, and has the scope for doing so. It is the emerging mastery of new routines that underlies a firm's progress down the learning curve. If very little change from the status quo is required, it follows that there is not much new for the firm to learn; hence, both the opportunity for, and the relative advantage from, learning will be relatively low. In contrast, when the innovating firm needs to overcome high uncertainty and complexity in order to bring its offer to market, the opportunity for learning will be higher, and so will be the potential for learning to be a source of competitive advantage. ${ }^{5}$

When the focal innovation requires accompanying innovations in components, the focal firm's development challenges increase, as it now must overcome additional hurdles in specifying, sourcing, and integrating new components into its new designs. These challenges can impact both the technological as well as organizational routines that must be mastered by the firm in

\footnotetext{
${ }^{4}$ The progress ratio measures the cost reduction associated with a doubling of production. A progress ratio of X\% implies that a doubling of production reduces cost of production to $\mathrm{X} \%$ of the initial cost.

${ }^{5}$ Balasubramanian and Lieberman (2006) report findings that are highly consistent with these arguments. They study 117 industries to examine how the relationship between experience and productivity depends on R\&D intensity (a proxy for industry development challenges). They find that greater R\&D intensity is correlated with lower progress ratios (i.e., greater learning potential).
} 
order for it to bring the innovative offer to the market. In this way, component challenges increase the magnitude of the firm's learning opportunity, and hence the advantage it can gain from progressing down the learning curve in advance of its rivals.

Further, the increased requirements for closer coordination with suppliers (Dyer and Singh, 1998) and more frequent iterations through design and development cycles (Clark and Fujimoto, 1991) that accompany challenging components, contribute not only to increasing the benefits to the technology leader from greater experience with the new technology, but also to reducing the ease with which later rivals can imitate this progress (e.g., Lippman and Rumelt, 1982; Rivkin, 2000). For example, rivals have found it difficult to imitate innovations that emerged from the extensive collaboration between Toyota and its key suppliers (Dyer, 1996; Dyer and Hatch, 2006).

\section{Hypothesis 1: Greater technological challenges in components will increase the performance advantage of technology leaders.}

The degree to which component challenges increase the performance advantage technology leaders may be tempered by the extent of modularity between the component and the focal product. Two mechanisms stand out when interfaces are well specified: first, with regard to the focal firm, there may be less potential for learning because key developments are undertaken by the supplier. Second, with regard to its rivals, there is the possibility that once the component has been developed for the technology leader, rivals can free ride on these investments and 'plugand-play' the component directly into their own offers, thereby reducing the leader's period of exclusivity in the market. 
We note, however, that while these factors can reduce the extent of a leader's advantage, they are unlikely to overturn it. While modularity does reduce interdependence, it does not eliminate it. For example, Brusoni and Prencipe (2001) note that while modularity allows for the rise of specialist component suppliers, it also poses greater organizational and knowledge requirements on the focal firms in their role as system integrators. Similarly, Hoetker's (2005) study of outsourcing choices in the notebook computer market supports the argument that organizational coordination challenges exist even when technologies are highly modular.

\section{Complement Challenges}

We have argued that component challenges can increase both potential for learning as well as barriers to imitation, and hence increase the advantages that accrue to technology leaders. How are the factors that support these advantages affected by challenges in complements? The resolution of component challenges is required in order for a firm to be able to produce its offer and present it to the market. However, the extent to which the offer can create value for users depends on the availability of critical complements. For example, the Airbus A380's ability to create value for its airline customers is hampered until airports, as key complementors, undertake the modifications to their terminals that are required to handle the oversized aircraft.

Many innovations rely on the availability of complements to unlock their full value. Rosenberg (1972) argues that a single innovation rarely constitutes a "complete innovation," and that the opportunities and challenges faced by users in adopting the innovation can be influenced by the state of development of complements. Hughes (1983) described imbalances in the pace of development of complementary innovations as creating "negative salients" on the frontier of technological development. Goldfarb (2005) offers a qualitative examination of how challenges 
in complements delayed the adoption of electricity in the railroad and printing industries in the early 1900s.

Greater complement innovation challenges result in delays in the availability of the complement as complementors struggle to overcome their technology hurdles. By reducing the value creation of the focal offer, delays in the availability of suitable complements act to slow the adoption rate of the new offer. These adoption delays impact the advantage from technology leadership in two distinct ways: First, they allow rivals more time to catch up, and possibly imitate the leader, before the market takes off. Second, because lower rates of adoption will reduce the firm ability to gain experience (i.e., lower demand will lead to lower production quantities), the leader will make slower progress down the learning curve during its period of exclusivity. Hence, even without imitation, later entrants will confront a leader with a smaller competitive advantage.

By acting to slow both adoption and the accumulation of experience, greater complement challenges erode the sustainability of the technology leader's competitive advantage.

Hypothesis 2: Greater technological challenges in complements will decrease the performance advantage of technology leaders.

The impact of complement challenges on technology leaders is likely to be affected by the extent to which complements are open vs. proprietary. When complements are open, such that they can be used with the offer of any firm, laggards will benefit from any progress that had been made in the market to advance the leader's offer; that is, spillovers will be higher and technology leaders will see their advantage eroded. 
When complements are proprietary, such that they can only work with the offer of a particular firm, spillovers will be reduced. However, the leader need not necessarily be better off: to the extent that there is a new development race to be won in the development of suitable complements, whether the first firm in the market with the focal offer will also win the race to be first to market with the key complement will depend on a number of case specific factors. What is clear, however, is that even when complements are proprietary, high complement challenges forces firms to compete in a second race for leadership. Hence, regardless of whether complements are open or proprietary, by putting their leadership into contention a second time, complement challenges erode the benefit of technology leadership in the focal offer.

\section{The balance of uncertainty: Technology vs. Opportunism}

Our discussion is focused on innovation challenges that arise in ecosystems, in which focal offers need to be combined with components and complements if they are to present a value creating solution to customers. We have argued that, in such contexts, the distribution of technology challenges across the ecosystem is an important driver of firms' outcomes. We now consider vertical integration as a governance strategy to manage such interdependence. ${ }^{6}$

A key benefit of vertical integration is the ability to mitigate contractual hazards. These contractual hazards arise when firms and their suppliers make asset specific investments under conditions of uncertainty (Williamson, 1985). When contracting with suppliers for innovative components with high development challenges, the focal firm faces two specific kinds of uncertainty. The first is the technological uncertainty surrounding whether and when suppliers

\footnotetext{
${ }^{6}$ In our empirical setting a subset of firms integrate into component production, but no firms integrate into complements. Hence, because we are only able to test arguments regarding vertical integration into components, we do not hypothesize about the benefits of integration choices with respect to complements. This question, although fascinating, lies beyond the scope of this paper.
} 
will discover appropriate solutions to their development challenges. The second is what Williamson terms behavioral uncertainty regarding whether and when suppliers will behave opportunistically to renegotiate agreements and reset terms in their own favor.

The resolution of technology uncertainty determines value creation - if the supplier cannot produce appropriate components, the firm cannot bring the desired product to market. The resolution of behavioral uncertainty determines value capture - if the supplier renegotiates the contract terms opportunistically, the firm cannot appropriate the expected rents.

Early in a technology's life cycle, technology uncertainty is at its peak. As development takes place, knowledge is accumulated and progress becomes more predictable. Although development continues throughout the lifecycle, and innovation challenges are always present, within a given trajectory the level of technology uncertainty tends to decrease over time (Dosi, 1982; Sahal, 1981). ${ }^{7}$

In contrast to technological uncertainty, which decreases with time, the trend for behavioral uncertainty as technology matures is ambiguous. On the one hand, increased experience and repeated interactions can allow firms to specify better formal contracts and extend relational contracts with their suppliers, such that behavioral uncertainty may decrease over time. On the other hand, it is also possible for behavioral uncertainty to increase over the technology life cycle: as firms continue to work with suppliers to improve their offers, the level of cospecialization, transaction specific assets, and supplier switching cost can increase. Similarly, as the market for the offer grows, so may the opportunity cost to the firm of switching suppliers and, hence, the incentive for suppliers to behave opportunistically. For example, the classic

\footnotetext{
${ }^{7}$ We distinguish between industry life cycles (i.e.,the time span between an industry's emergence and its decline) and technology life cycles (the time span between a technology generation's emergence and its decline). In this paper our discussion is held at the level of the technology life cycle of specific technology generations, and hence at a different level of analysis than the industry's broader evolution (e.g., Stigler, 1951).
} 
episode of General Motors and Fisher Body as discussed by Klein (1988, 2000) suggests that the rapid increase in demand for closed metal bodies created significant contractual hazards for GM and led GM to acquire Fisher Body.

Vertical integration mitigates the effects of behavioral uncertainty but not of technology uncertainty. As the level of technology uncertainty decreases over the technology's life cycle, the relative importance of behavioral uncertainty rises. Hence, the benefit from vertical integration will be greater at later stages of the technology life cycle.

Hypothesis 3: The performance advantage from vertical integration will increase over the course of the technology life cycle.

\section{EMPIRICAL CONTEXT}

We test our hypotheses in the context of the semiconductor lithography equipment industry. Semiconductor lithography is a key process used by semiconductor manufacturers to create integrated circuits. Improvements in lithography tools have been the main driver of progress in semiconductor manufacturing, enabling the production of higher performance chips at lower marginal cost (Moore, 1995). From its emergence in 1962 to 2005, the semiconductor lithography industry has witnessed the commercialization of 9 different technological generations. From the beginning, lithography tool manufacturers have regarded technology leadership to be a key source of competitive advantage. Being among the first to introduce a new technology generation offers technology leaders significant learning advantages as well as the opportunity to lock in customers due to high switching costs. 
In each of the nine technology generations the manufacturers of lithography tools had to overcome significant innovation challenges. Although suppliers and complementors were always critical to enabling each new technology generation, the magnitude of their challenges varied across generations - whereas in some generations it was possible to simply reuse existing elements, other generations required suppliers and complementors to completely reinvent their offers.

\section{Semiconductor Lithography}

Semiconductor lithography is the process by which a circuit design is imprinted on a semiconductor wafer. The basic principle of lithography is illustrated in Figure 2. After the design of an integrated circuit (IC) is finalized (i.e., the wiring, the gates and the junctions), the circuit blueprint is transferred to a "mask". The lithography process takes place when beams of energy originating from an "energy source" are directed onto the mask. The pattern on the mask allows a portion of the energy to pass through, with or without an optical "lens" system, onto the wafer. The wafer is coated with an energy sensitive "resist". The resist undergoes a chemical reaction wherever the mask has allowed the energy to pass through. This chemical reaction changes the structure of the resist and allows its selective removal from the wafer. Another chemical process is then initiated in which the exposed parts of the wafer are etched. Finally, the remaining resist is removed, creating a final circuit that replicates the initial design. A single wafer can go through this process a number of times as multiple layers of circuits are etched on to it. For example, in 2006, a one gigabit DRAM chip could be etched with as many as sixty circuit layers.

(Insert Figure 2 about here) 
The key performance attribute of a lithography tool is its resolution, the smallest geometry on which the tool can focus on the wafer surface. Resolution determines the extent of miniaturization that can be achieved by the semiconductor manufacturer. A semiconductor manufacturer will use scores of lithography tools in a single production line, often one for each circuit layer. With modern tools costing over twenty million dollars each, investments in lithography equipment represent a substantial portion of the cost of a fabrication facility. Lithography "production recipes," which are customized to specific tool models, masks and resists, are regarded as a key source of advantage for semiconductor manufacturers, who invest significant resources in optimizing their production lines (Iansiti, 1997). To maintain competitiveness semiconductor manufacturers continuously reinvest in their facilities and look to new tool generations to allow them to offer products with higher performance at lower cost.

In this study, our focal firms are the firms that design and assemble the lithography tool. The key components that these tool makers need to integrate into their offers are the energy source and the lens. Their customers are semiconductor manufacturers who use the lithography tool in their fabrication plants. The mask and the resist are the key complements that these customers must integrate with the lithography tool. A schema of the lithography tool ecosystem is presented in Figure 3.

\section{(Insert Figure 3 about here)}

The development of a new generation of tool technology poses significant challenges for tool manufacturers to achieve finer and finer resolutions. A new tool generation can also impose significant challenges on other ecosystem elements: the energy source may need to operate at a 
new wavelength; the lens may need to be manufactured from a new material; the mask, which needs to be etched with thinner lines, may need to be manufactured in a new way, possibly from new materials; the chemical resist may need to be reformulated to allow for greater control of the chemical reactions as energy wavelengths become smaller and geometric resolutions become finer.

Despite undergoing nine generational transitions, the structure of interdependence in the ecosystem - the components that need to be integrated by the focal tool manufacturers and the complements that their customers, the semiconductor manufacturers, need to combine with the tool offer - has remained unchanged throughout the forty-four year period that we study. All tool manufacturers integrate the source and lens components and leave it to their customers to integrate the mask and the resist complements with the tool. This choice of what to bundle and what to exclude in the tool offer is rooted in a lack of synergies on both the supply- and demandsides. On the supply side, there is little overlap between the knowledge bases and resources required to succeed in developing and assembling lithography tools (highly complex batch assembly), creating new resists (producing vats of very specialized chemical solution) and mask production (essentially a custom printing service business with a heavy consulting aspect). More importantly, on the demand side, the big semiconductor manufacturers (the tool makers' most important customers) have had little interest in fully bundled solutions - they regard their proprietary production recipes for putting together tool, mask, and resist as a key source of their own competitive advantage (Kapoor and Adner, 2008), and view a move to bundled lithography solutions as inviting a loss of differentiation. ${ }^{8}$ Where firms have differed, is in their strategy for

\footnotetext{
${ }^{8}$ Such stability in activity flows is a common characteristic across many industries. For example, automakers have historically bundled the components of wheels and engines into their car leaving it to their customers to bundle the car with fuel and roads. Similarly, disk drive producers have always bundled motors and heads; their customers, the computer assemblers, bundle the drive with processors and software.
} 
managing their interdependence with components: some firms are vertically integrated into lens production whereas others rely on external suppliers.

Thus, the industry allows us to examine a well defined technological ecosystem comprised of focal firms, their suppliers, and their complementors, in which the location and magnitude of ecosystem innovation challenges vary across technology generations. The industry is also appealing because it provides a natural set of controls for two key factors that have already been examined in the innovation literature. First, all the transitions across technology generations can be characterized as sustaining innovations (non-disruptive in the Christensen, 1997 sense) in that all technology generations were targeted at existing customers, enhanced performance on the same set of key performance attributes (resolution, accuracy, and throughput, in particular), and commanded significant price premiums over earlier generations. Second, the value of complementary assets - sales force, manufacturing, brand, service and support competence were preserved throughout, such that the concerns of Mitchell (1989) and Tripsas (1997) are essentially controlled for.

\section{Technology Transitions in the Semiconductor Lithography Equipment Industry}

The key measure of progress in semiconductor lithography is improvement in tool resolution. Finer resolutions allow the semiconductor manufacturers to use the lithography tool to pack more circuits onto a chip and more chips onto a wafer. These improvements allow semiconductor manufacturers to offer chips with higher performance at lower marginal cost.

For the lithography tool manufacturers this means that improving resolution is a top priority. Tool manufacturers increase resolution using a combination of three levers. The first is to reduce the wavelength of light that is transmitted by the energy source. The second is to 
increase the size of the lens. The third is to improve the design of the tool itself. The industry distinguishes among technology generations according to the design of the tool and the wavelength of energy that it transmits. Incremental improvements to the tool design and the lens are core drivers of advance within a technology generation. When further improvements become untenable, due to a combination of physical and economic constraints, the industry shifts to a new design or to a smaller wavelength, which heralds the emergence of a new lithography tool generation.

In transitioning across technology generations, tool manufacturers always faced significant design challenges. Consider, for example, the industry's transition from I-line steppers to DUV 248nm steppers. The core approach to increasing resolution in this transition was to decrease the energy wavelength from $365 \mathrm{~nm}$ to $248 \mathrm{~nm}$, which would allow tool resolution to improve from $0.8 \mu \mathrm{m}$ to $0.45 \mu \mathrm{m}$. The relationship between reduced wavelength and finer resolution is straightforward in theory. ${ }^{9}$ Realizing this improvement in a commercial setting, however, requires a corresponding improvement in tool design (e.g., in terms of factors such as alignment, repeatability, reliability, and throughput). Overcoming these design challenges requires tool manufacturers to experiment and iterate, often for years, in order to come up with a suitable offer (Henderson and Clark, 1990). ${ }^{10}$

When a new tool generation requires innovation in components, the tool manufacturers face greater challenges in specifying, sourcing, and integrating the new components into their

\footnotetext{
${ }^{9}$ The resolution capability of lithography technologies that employ a lens system is given by the Rayleigh criterion: Resolution $=k_{1} x$ (Wavelength/Numerical Aperture)

where wavelength is the wavelength of the light being transmitted by the source, numerical aperture is the measure of the size of the lens, and $\mathrm{k}_{1}$ is a process-specific constant.

${ }^{10}$ Henderson's studies of the industry have highlighted that in confronting new technology generations firms may face both engineering challenges in creating new designs, as well as cognitive challenges in recognizing the subtleties of change (Henderson and Clark, 1990; Henderson, 1993). In particular, she highlighted the unique cognitive challenges that confront incumbents when generational changes affect the architectural links among only core design concepts. The focus of our paper is on external challenges; however, we account for incumbency effects in our empirical specification.
} 
designs. The transition to DUV 248nm, for example, required fundamental changes in the energy source and the lens. Mercury lamps, which had been used in all earlier generations, were not able to provide sufficient energy at a wavelength of $248 \mathrm{~nm}$ to cause adequate chemical reactions in the resist. This challenge was overcome by the development of excimer lasers using Krypton Fluoride $(\mathrm{KrF})$ gas. The conventional glass material that had been used to make lenses faced absorption problems with the $248 \mathrm{~nm}$ wavelength. The only material that could be used was fused silica, and this required major changes to the lens manufacturing process. These required changes created significant challenges in components, which, in turn, served to increase the design and integration challenges that confronted the tool manufacturers.

In order for the new generation tools to be used effectively, significant challenges needed to be overcome in the development of the complements as well. Mask makers needed a new material that would provide improved transmission of the new wavelength which, in turn, required changes to the mask manufacturing process. Finally, the existing novolac resists could not absorb enough energy from the $248 \mathrm{~nm}$ wavelength to cause an adequate chemical reaction. To solve this challenge, a new chemically-amplified resist had to be developed.

Table 1 summarizes the major technological innovations required to overcome the challenges in the tool, lens, source, mask, and resist in each technology generation. A more detailed overview of each of the technology transitions is presented in Appendix I.

(Insert Table 1 about here) 


\section{METHODOLOGY}

\section{Data}

We used both primary and secondary data sources for this study. We began by developing a detailed historical understanding of the semiconductor lithography equipment industry during a 20-month field study. We conducted multiple interviews with over thirty industry experts, most of whom have been associated with the industry for more than twenty years. The interviewees came from a variety of positions within the ecosystem: tool makers, semiconductor manufacturers, suppliers, complementors, industry associations, and consultants. The interviews were semi-structured and lasted two hours on average. We identified ecosystem structure by asking first, what elements needed to be integrated by tool manufacturers in order for them to produce their offers; and second, what elements needed to be integrated by the tool customers in order for the tool to be used productively. There was unanimous agreement that the energy source and the lens were the key components to be integrated into the tool by the manufacturer, and that the mask and the resist were the key complements to be integrated with the tool by the customer. We used the information from the interviews to develop an understanding of the ecosystem challenges that governed the emergence of the different technology generations. We consolidated this information in a document that mirrors Table 1 and sent it back to our interviewees for written and verbal comments. We incorporated these comments and then sent the table out for a second review. All the experts agreed with our final characterization. In addition, we used our field work to develop a list of keywords that we used to guide the article search that we used to create our measures of component and complement challenges. ${ }^{11}$

\footnotetext{
${ }^{11}$ The keywords were: lithography, microphotographs, mask, photomask, resist, laser, UV, DUV, Deep UV, optical, lens, stepper, aligner, mercury, illuminator, exposure, printer and the names of the different generations
} 
We searched every issue of Solid State Technology from 1961 to 2001 for articles relating to ecosystem innovation challenges. Solid State Technology is a leading industry journal whose mission is to cover the key trends and issues that confront the industry. It has been publishing technical articles on challenges facing the semiconductor industry since its founding. Using this source, we created measures (discussed below) that characterize the extent of challenges in the key components and complements for each of the technology generations.

Finally, we obtained detailed market data from the leading industry consulting firm, VLSI Research, which has been following the industry since early 1970's. The VLSI data included sales by technology generation for every firm that competed in the lithography equipment industry from 1974 to 2005 . Rebecca Henderson generously shared her data on the contact printing generation. Our final data set consists of an unbalanced panel of 64 firm-technology generations. The average number of observations per group is 10.4. Our data is comprehensive and includes information on each of the 33 firms that ever sold a semiconductor lithography tool. $^{12}$

\section{Variables}

The definitions of the variables used to test our hypotheses are summarized in Table 2 and detailed below.

(Insert Table 2 about here)

\footnotetext{
${ }^{12}$ In our analysis we exclude 2 firms from our sample because, although they produced lithography tools, they were competing in different markets. These firms entered the given lithography generation during its declining phase and were targeting niche markets such as thin film heads, pressure sensors, and biotech applications rather than the mainstream applications of semiconductor manufacturers.
} 


\section{Dependent Variable}

Our dependent variable, generation share, is a firm's market share in a given technology generation in a given year. This measure is consistent with prior studies that examine firm performance in new technology generations (e.g., Mitchell, 1991; Henderson, 1993; Tripsas, 1997). Further, industry participants and observers (e.g., VLSI Research, Gartner Dataquest) regularly use market share in a generation as a measure of firm success.

In our main analysis we consider a firm's market share in a given technology generation in a given year. As a test of robustness for hypotheses 1 and 2, reported in Appendix II, we also consider a firm's cumulative market share over the entire life of the technology generation.

\section{$\underline{\text { Independent Variables }}$}

Our measures of component and complement challenges were created using a count of Solid State Technology articles. Our industry sources confirmed that a count of published articles that address technical problems regarding an ecosystem element is a good proxy for the level of technology challenges that surrounded the development of different lithography generations. We identified a total of 181 lithography related articles that appeared from 1961 to 2001 . We then identified articles that discussed ecosystem challenges in a given generation. We used the article titles to identify the match between the generation and the ecosystem element. If insufficient information was available in the title, we read the abstract and the conclusion to ascertain if the article addressed the innovation challenges in the ecosystem for a given generation. This reduced our set to 102 articles.

Finally, since our primary concern is with respect to innovation challenges that confront technology leaders as they pioneer new technology generations, we further reduced our set to 
include only those articles that were published no later than 5 years after the commercialization of the first tool in a generation. Another reason to choose the 5 year post-commercialization window was to present a balanced view of upstream and downstream ecosystem challenges. The articles that were published after the close of this 5-year window were almost entirely dedicated to discussing complement challenges. This is not surprising, since by the $5^{\text {th }}$ postcommercialization year, much progress would have necessarily been made on the component side. We tested robustness with 3- and 7-year windows and the results are consistent with the ones reported here. A small subset of articles compared the ecosystem innovation challenges for different generations, and for these articles we read the relevant sections for each generation in order to create a match. This reduced the set to 56 articles that discussed 78 ecosystem innovation challenges.

We constructed the Component Challenge measure as the sum of the number of articles that discussed innovation challenges in the lens $\left(\right.$ Innov $\left._{l g}\right)$ and the source $\left(\right.$ Innov $\left._{s g}\right)$ for technology generation $g .{ }^{13}$

Component Challenge $_{g}=$ Innov $_{l g}+$ Innov $_{s g}$

Similarly, Complement Challenge was constructed as the sum of the number of articles that discussed innovation challenges in the resist $\left(\right.$ Innov $\left._{r g}\right)$ and the mask (Innov $\left.v_{m g}\right)$.

Complement Challenge $_{g}=$ Innov $_{r g}+$ Innov $_{m g}$

\footnotetext{
${ }^{13}$ As validation of the article count measure, we tested its consistency with the qualitative descriptions revealed in our interviews and reported in Table 1 . We coded the entries and non-entries in Table 1 with values of one and zero respectively, and then compared them to the article count data. The correlation is 0.91 for source, 0.83 for lens, 0.92 for mask and 0.89 for resist innovation challenges. This high correlation increases our confidence in the measure.
} 
We measure a firm's Technology Leadership as the time of its entry into a new technology generation relative to its rivals. We define entry as the first occurrence of revenue for a firm in a given generation. The first firm to enter the generation was assigned a technology leadership value of 1 . Subsequent firms were assigned values with reference to the years elapsed since the first entrant (e.g., a firm entering a generation three years after the leader was assigned a technology leadership value of 4).

To assess the effects of vertical integration on firm performance we construct the variable Vertical Integration. The variable takes a value of 1 if the firm produced its own lens component in a given technology generation and 0 otherwise. During the history of the industry no tool manufacturer produced its own energy source.

We defined the variable Technology Maturity as the number of years that have lapsed since the first commercial sale of a tool in the given technology generation, where the first year of commercial sales is coded as 1 .

\section{$\underline{\text { Control Variables }}$}

We control for a number of firm and industry level effects. The prior literature (e.g., Henderson and Clark, 1990) has identified important differences between incumbents and entrants during regimes of technological change. We controlled for this effect using the variable Incumbent, which takes a value of 1 if a firm had sold lithography tools in an earlier technology generation.

We controlled for firm size through the variable Conglomerate, which takes a value of 1 if the firm was active in industries other than semiconductor manufacturing equipment and 0 
otherwise. We have two industry level controls. The first is Generation Sales Growth, a measure of change in tool sales (in dollars) in a given generation in a given year, which represent the growth opportunities that may influence choices regarding investment in new technology generations. The second is Number of Firms, which controls for the competitive density in the generation in a given year.

\section{Statistical Analysis}

We use panel data for our empirical analysis. The use of panel data helps to control for potential sources of unobserved heterogeneity and allows us to test how the benefits of vertical integration change over time during the course of a given generation. While both the random and the fixed effects models allow for explicit consideration of the unobserved firm effect, the random effects model makes an additional assumption that the unobserved firm effect is uncorrelated with the independent variables. Although a fixed-effects approach would require fewer assumptions than the random-effects approach, it cannot be used if the explanatory variables do not vary within the experimental group (Baltagi, 2005; 13). In our analysis component challenges and complement challenges are the key explanatory variables, but they do not exhibit inter-temporal variation for a firm within a given generation. For this reason, we use a random effects model. As discussed by Wooldridge (2002), in a random effects estimation, we can attempt to control for unobserved differences across firms by including firm dummies. Hence, we test our hypotheses using a random effects model and include both firm and year dummies as controls for unobserved firm- and year-specific effects. We estimate the following equation:

$$
\mathrm{y}_{i g t}=\beta_{0}+\mathbf{X}_{i g t} \boldsymbol{\beta}+\mathbf{D}_{i} \lambda+\mathbf{T}_{t} \boldsymbol{\delta}+\mathrm{a}_{i g}+\mathrm{u}_{i g t}
$$


where $\mathrm{y}_{\text {igt }}$ is firm i's market share in a generation $\mathrm{g}$ in year $\mathrm{t} ; \mathbf{X}_{\text {igt }}$ is the vector of independent and control variables; $\mathbf{D}_{i}$ is the vector of dummies for each firm; $\mathbf{T}_{t}$ is the vector of dummies for each year; $\mathrm{a}_{i g}$ is the unobserved heterogeneity for a firm in a generation that is assumed to be uncorrelated with the explanatory variables; and $\mathrm{u}_{i g t}$ is the error term.

As a further test of robustness for Hypotheses 1 and 2, in Appendix II we include a cross sectional OLS specification in which the dependent variable is the firm's cumulative market share in a generation (total firms sales in generation ${ }_{g} /$ total sales in generation $\left._{\mathrm{g}}\right)^{14}$

\section{RESULTS}

\section{Descriptive Relationships}

Figure 4 illustrates the varying degrees of component and complement challenges in each of the nine technology generations. As can be seen from the figure, each of the technology generations presented a distinct combination of ecosystem challenges. This is a key source of variance that we exploit in this study.

(Insert Figure 4 about here)

\footnotetext{
${ }^{14}$ As an additional test of robustness for hypotheses 1 and 2, to help assure that our observed effects are not due a firm endogeneity bias, we reconfigured our panel data from grouping by "firm in a generation" to grouping by "firm". This specification allowed us to estimate a traditional fixed effects specification. However it required that we rightcensor observations of firms' participation in older generations beginning in the year in which they introduce their new generation offers (because the panel can only have one observation per firm per year). In addition, because the fixed effects estimation requires temporal variance within a panel, it effectively excludes firms that participated in only one technology generation. These exclusions reduced the number of observations from 676 to 406 . The results of this more conservative test, available from the authors. are fully consistent with those presented here. Because the right censoring required for estimating this specification precludes us from testing hypothesis 3 , we report the random effects model with firm and year dummies in the main results.
} 
The descriptive statistics and pairwise correlations for the variables used in the study are presented in Table 3. The significant negative correlation between technology leadership (where lower values indicate earlier entry timing) and generation share suggests that early entry is rewarded with higher market share in the semiconductor lithography equipment market. Since component challenges and complement challenges are moderately correlated, we enter these variables into separate models to alleviate concerns regarding multicollinearity.

(Insert Table 3 about here)

\section{Tests of the Hypotheses}

Our hypotheses predict the impact of external ecosystem challenges on the performance advantage that accrues to technology leaders, and the impact of vertical integration decisions on this performance over the course of the technology life cycle. We test Hypotheses 1 and 2 by interacting firms' technology leadership with measures of ecosystem challenges. We meancenter the variables in the interaction terms. The mean-centering of continuous variables helps to reduce potential multicollinearity and facilitates the interpretation of the estimated coefficients (Aiken and West, 1991). We test Hypothesis 3 by interacting firms' vertical integration status with the generation's technology maturity. Consistent with prior studies examining market share performance in new technology generations (e.g. Henderson, 1993; Tripsas, 1997), we use a semi-log specification to test our hypotheses.

Table 4 reports our regression results. Model 1 is our baseline model. Consistent with conventional wisdom in the industry, the coefficient for technology leadership is significant and negative, indicating benefits to technology leadership. We find that incumbency has a negative 
effect, which is consistent with Henderson's (1993) findings in her study of the industry. The coefficient for vertical integration is significant and positive, suggesting that in-house component manufacturing is a source of advantage in this industry. The coefficient for complement challenge is significant and positive. While not hypothesized, this finding indicates that high complement challenges may increase the market share of an average firm. Since average firms are technology followers, this is consistent with the mechanisms that underlie Hypothesis 2. Among the industry level controls, the coefficient for number of firms is negative and significant, confirming the negative effects of competitive density on firms' market share performance.

In Model 2 we interact technology leadership with component challenge to test Hypothesis 1. In Model 3 we interact technology leadership with complement challenge to test Hypothesis 2. In Model 4 we interact vertical integration with technology maturity to test Hypothesis 3. Model 5 is the fully specified model.

(Insert Table 4 about here)

In Hypothesis 1 we predicted that greater component challenges will increase the performance advantage accorded to technology leaders. The hypothesis is supported in Models 2 and 5. The coefficient of the interaction term between technology leadership and component challenge is negative and significant. Hence, the greater the challenges in components, the greater the benefits that accrue to technology leaders.

In Hypothesis 2 we predicted that greater complement challenges will decrease the performance advantage accorded to technology leaders. The hypothesis is supported in Models 3 and 5. The coefficient of the interaction term between technology leadership and complement 
challenge is positive and significant. Hence, complement challenges in the firms' ecosystem erodes the benefits that accrue to technology leaders.

In Hypothesis 3 we predicted that the advantage from vertical integration will increase over the course of the technology life cycle. The positive and significant coefficient of the interaction term between vertical integration and technology maturity in Models 4 and 5 supports the hypothesis.

We tested the robustness of our results in a number a ways. First, as a test of robustness for Hypotheses 1 and 2, we include in Appendix II results from a cross sectional specification estimated using OLS regression for a firm's cumulative market share in a given generation. The results are fully consistent with our predictions.

Second, we considered the X-ray and E-beam generations as possible anomalies. These were the only technology generations not to achieve market dominance even in their peak sales years. This however, was only evident ex post. Ex ante, these two generations had garnered very strong interest and support among industry participants, who believed that these generations represented the future of lithography technology. As a robustness test, we present Model 6 in Table 4, which excluded the X-ray and E-beam technology generations and whose results are fully consistent with our predictions.

Finally, we split component and complement challenges into their individual elements of source, lens, mask and resist to make sure that our results are not driven by a specific element. Again, the results are fully consistent with the predictions. 


\section{DISCUSSION}

Successful innovation depends on a firm's ability to resolve the uncertainties that surround the development and production of its offer. These challenges have long been a focus of both the academic and applied innovation literatures. We note, however, that the literature's overwhelming focus has been on the management of firms' internal innovation challenges. In this paper we have explicitly focused on the neglected role of external challenges in driving innovators' outcomes.

In considering external innovation challenges, we present a structured framework to distinguish between those challenges whose resolution depends on suppliers and those whose resolution depends on complementors. We find that, depending on their location, challenges in the external ecosystem can either enhance or erode a firm's competitive advantage from technology leadership. Specifically, we find that while the advantage from technology leadership increases with component challenges, it decreases with complement challenges. Challenges in components increase the technology leader's competitive advantage by increasing the potential for learning and by increasing barriers to imitation. In contrast, challenges in complements reduce the technology leader's competitive advantage by slowing its advance down the learning curve and increasing opportunities for rivals to catch up.

Figure 5 uses the estimates from Model 5 to plot the effect of technology leadership on firms' market share performance for different combinations of ecosystem challenges. The vertical axis is the difference in average annual market share between the technology leader, who enters the generation in year 1 , and a follower, who enters in a later year. The horizontal axis is the follower's year of entry. We plot three component-complement uncertainty scenarios, where high (low) corresponds to a $+1(-1)$ standard deviation above (below) our sample mean. The 
baseline case, "low component-, low complement- challenge" shows a downward sloping curve, indicating that when ecosystem challenges are low the technology leader is advantaged relative to the follower. As discussed above, this is highly consistent with well established industry beliefs. In the case of "high component-, low complement- challenge" we find that the slope is even more negative, indicating that technology leaders enjoy an even greater competitive advantage. To get a sense for the economic magnitude of these differences, consider that in 2004 a $1 \%$ market share difference in the DUV 248 generation corresponded to $\$ 28.7$ million in sales. Finally, in the "low component-, high complement- challenge" case we find a weakly upward sloping curve. This indicates that when complement challenges are high, technology leadership is less beneficial; indeed, in our specific context, we find that the leader is at a slight disadvantage to later followers. (Insert Figure 5 about here)

The implication of Figure 5, as an illustrative summary of our arguments and findings, for the debates regarding early mover advantages is a strong one. Moving beyond the debate of existence vs. non existence of first mover advantages (e.g., Golder and Tellis, 1991; Leiberman and Montgomery, 1988, 1998), we have identified specific contingencies that determine the value of technology leadership. Further, the mechanisms that we identify regarding the opposing effects of component and complement challenges expand the analysis of first mover advantage beyond the traditional firm-centered focus to incorporate specific features of the external environment.

Beyond environmental contingency, we also examine vertical integration as a strategy for managing ecosystem challenges. We argue that when contracting with suppliers for innovative components, the focal firm faces two specific kinds of uncertainty. The first is the technological 
uncertainty surrounding whether and when suppliers will discover appropriate solutions to their own development challenges. The second is the behavioral uncertainty regarding whether and when suppliers will behave opportunistically to renegotiate agreements and reset terms in their own favor. We note that while technology uncertainty is resolved and reduced over the course of the technology lifecycle, behavioral uncertainty does not necessarily decrease over time. This asymmetry suggests that the balance between technology uncertainty and behavioral uncertainty will tend to tilt towards the latter over time. As such, we argue and find that the benefits derived from vertical integration increase over the course of the technology life cycle. This finding is consistent with recent studies conducted in the context of the automotive industry (Argyres and Bigelow, 2007; Novak and Stern, 2008).

Distinguishing between innovation challenges that lie upstream and downstream of a focal firm reveals important asymmetries in their effect on the firm's ability to create value with its offer. The impact of upstream component challenges, which prevent the firm from offering its innovation to the market, are qualitatively different from downstream complement challenges, which prevent the focal firm's customers from utilizing the innovation to its full potential. Whereas the former constitute barriers to production, the latter are barriers to adoption. Although both result in bottlenecks to value creation, they have opposite effects on the firm's ability to capture value and create competitive advantage. This finding supports recent calls in the literature that argue for the importance of understanding the dynamics of value creation as a precursor to the analysis of value capture (e.g., Brandenburger and Stuart, 1996; Adner and Zemsky, 2006). 
This study, of course, has a number of limitations. First, it explores a single industry, raising questions of generalizability. Second, it does not have a direct measure of focal firms' innovation challenges.

Our field interviews indicate that these were consistently high across generations, but that

. They did, however vary depending on While we have taken care in our estimation and included firm and year dummies to account for unobserved differences across firms and time periods, there are several potential concerns with respect to endogeneity. We have taken a number of steps to alleviate these

This study, of course, has a number of limitations. While we have taken care in our estimation and included firm and year dummies to account for unobserved differences across firms and time periods, there are several potential concerns with respect to endogeneity. First, our focus is on the effect of component and complement challenges that arise during technology transitions. During these transitions focal firms also faced innovation challenges in their core activities, but due to non-availability of data we were unable to measure their extent. This omission could bias our results if focal innovation challenges were correlated with external challenges. However, descriptive evidence suggests that there is no systematic correlation between the core innovation challenge and challenges in components and complements. For example, in the proximity generation, while the tool manufacturers faced significant challenges in designing and manufacturing the new architecture, there were no major changes required anywhere else in the ecosystem. For completeness, we do control for the fact that incumbents are likely to face greater challenges across the technological transitions than entrants as discussed by Henderson and Clark (1990) and find support for this argument. Second, it is possible that 
vertically integrated firms may systematically enter a generation late and ramp up much faster than their non-integrated rivals. We checked for this possibility by comparing the technology leadership values for integrated with those of non-integrated firms. We did not find a significant difference between the two sub-groups $(\mathrm{t}=0.90, \mathrm{p}=0.37)$. In addition, we performed a robustness test by excluding the data for the first two years of each firm's participation in a new technology generation. In our context, the first two years are typically characterized by ramp-up challenges. Our predicted relationship continued to be significant. Third, we characterize the location relationships among ecosystem actors, but we have no visibility as to the history and nature of specific exchange relationships among these actors, and how these might affect their interactions (e.g., Argyres and Liebeskind, 2002). Future studies could address these limitations by incorporating how actors coordinate, through mechanisms such as alliances, and relational contracts, within the context of innovation ecosystems. Finally, this study is conducted in the context of a single industry, such that its replication in other contexts would extend its generalizability.

This study has presented an ecosystem lens to examine the conditions under which technology leadership yields competitive advantage. We have argued and shown that the benefit of technology leadership depends on both the location and the magnitude of uncertainty within the ecosystem. We have examined the effectiveness of vertical integration as a strategy to manage ecosystem uncertainty and have identified the impact of the technology lifecycle in determining its benefits.

Ecosystem settings raise a new set of issues for both researchers and managers to consider. Choices regarding both business model design and organization design need to be revisited in the light of joint value creation. Questions regarding development incentives 
(Cassadesus-Masanell and Yoffie, 2005), positioning and coordination choices (Iansiti and Levien, 2004; Gawer and Cusumano, 2002), customer expectations (Tripsas, 2006; Adner, 2004), and value chain configuration (Jacobides and Billinger, 2006) all become more visible and more important in the context of ecosystems. We hope that our framework and analysis can offer additional avenues through which such questions can be fruitfully addressed. 


\section{REFERENCES}

Adner, R. 2004. A demand-based perspective on technology lifecycles. Advances in Strategic Management.

Adner, R. 2006. Match your innovation strategy to your innovation ecosystem. Harvard Business Review, 84(4): 98107.

Adner, R. and Zemsky, P. 2006. A Demand-Based Perspective on Sustainable Competitive Advantage." Strategic Management Journal, 27(3): 215-239.

Afuah, A \& Bahram, N. 1995. The hypercube of innovation, Research Policy, 24(1): 51-76.

Afuah, A. 2000. How much do your co-opetitors' capabilities matter in the face of technological change? Strategic Management Journal, 21(3): 387-404.

Aiken, L. S., \& West, S. G. 1991. Multiple regression: Testing and interpreting interactions. Newbury Park, CA: Sage.

Argote, L. 1999. Organisational Learning: Creating, Retaining and Transferring Knowledge. Norwell, MA: Kluwer Academic Publishers.

Argyres, N.S. and Liebeskind, J. P. 200.2 Governance Inseparability and the Evolution of the Biotechnology Industry. Journal of Economic Behavior and Organization,. 47, pp. 197-219.

Argyres, N. and Bigelow L. 2007. Does Transaction Misalignment Matter for Firm Survival at All Stages of the Industry Life Cycle? Management Science. 53(8):1332-1344.

Balasubramanian, N. and Lieberman, M.B., 2006, Industry Learning Environments and the Heterogeneity of Firm Performance. Working paper.

Baltagi, B. 2005. Econometric Analysis of Panel Data (3rd ed.). New York: John Wiley \& Sons.

Brandenburger, A. M., \& Nalebuff, B. J. 1997. Co-Opetition: A Revolution Mindset That Combines Competition and Cooperation; The Game Theory Strategy That's Changing the Game of Business. New York: Currency.

Brusoni, S. and Prencipe, A. 2001. Unpacking the Black Box of Modularity: Technologies, Products and Organizations. Industrial and Corporate Change, 10: 179-205.

Brusoni, S., Prencipe, A., \& Pavitt, K. 2001. Knowledge specialization, organizational coupling, and the boundaries of the firm: why do firms know more than they make? Administrative Science Quarterly, 46: 597-621.

Casadesus-Masanell, R., \& Yoffie, D. B. 2005. Wintel: Cooperation or Conflict. Harvard Business School Working Paper.

Christensen, C. M. 1997. Innovator's Dilemma: When New Technologies Cause Great Firms to Fail. Boston: Harvard Business School Press.

Christensen, C. M., \& Rosenbloom, R. S. 1995. Explaining the attacker's advantage: Technological paradigms, organizational dynamics, and the value network. Research Policy, 24(2):233-257.

Christensen, C. M., Suárez, F. F., \& Utterback, J. M. 1998. Strategies for survival in fast-changing industries. Management Science, 44(12): S207-S220.

Clark, Kim B., and Fujimoto, T. 1991. Product Development Performance. Harvard Business School Press, Boston, MA.

Cooper, A. C., \& Schendel, D. 1976. Strategic response to technology threats. Business Horizons, 19(1): 61-69.

Dosi, G. 1982. Technological Paradigms and Technological Trajectories. Research Policy, 11: 147-162.

Dutton, J. and Thomas, A. Treating Progress Functions as a Managerial Opportunity The Academy of Management Review. 9(2): 235-247.

Dyer, J.H. 1996. Specialized supplier networks as a source of competitive advantage: Evidence from the auto industry. Strategic Management Journal 17(4):271-291.

Dyer, J.H. and Singh, H. The Relational View: Cooperative Strategy and Sources of Interorganizational Competitive Advantage The Academy of Management Review, 23(4): 660-679.

Eisenhardt, K.M. 1989. Making Fast Strategic Decisions in High-Velocity Environments." Academy of

Gawer, A., \& Cusumano, M. A. 2002. Platform Leadership: How Intel, Microsoft, and Cisco Drive Industry Innovation. Boston: Harvard Business School Press.

Golder, P.N. and Tellis, G.J. 1993. Pioneer advantage: Markeitng logic or marketing legend? Journal of Marketing Research, 30(2): 158-170 
Goldfarb, B. 2005. Diffusion of general-purpose technologies: understanding patterns in the electrification of US Manufacturing 1880-1930. Industrial and Corporate Change, 14(5): 745-773.

Henderson, R. 1993. Underinvestment and incompetence as responses to radical innovation: evidence from the photolithographic alignment equipment industry. RAND Journal of Economics, 24(2): 248.

Henderson, R. M. 1995. Of life cycles real and imaginary: The unexpectedly long old age of optical lithography. Research Policy, 24(4): 631.

Henderson, R. M., \& Clark, K. B. 1990. Architectural innovation: The reconfiguration of existing product technologies and the failure of. Administrative Science Quarterly, 35(1): 9-30.

Hoetker, G.. 2006. Do modular products lead to modular organizations? Strategic Management Journal, 27(6):501518.

Hughes, T. P. 1983. Networks of Power: Electrification in Western Society 1880 - 1930. Baltimore: Johns Hopkins University Press.

Iansiti, M., \& Levien, R. 2004. The Keystone Advantage: What the New Dynamics of Business Ecosystems Mean for Strategy, Innovation, and Sustainability. Boston: Harvard Business School Press.

Iansiti, Marco 1997. Technology Integration: Making Critical Choices in a Dynamic World. Harvard Business School Press Integration. Boston: Harvard University.

Intel Corporation. 2004. "Intel Sees Unified Platform And Ecosystem As Key To Enabling The Digital Home" Press release. Feb. 17.

Jacobides, M. G., \& Billinger, S. 2006. Designing the Boundaries of the Firm: From Make, Buy, or Ally to the Dynamic Benefits of Vertical Architecture. Organization Science, 17(2): 249-261.

Kapoor, R. and Adner, R. 2007. Technology Interdependence and the Evolution of Semiconductor Lithography. Solid State Technology 50(11): 51-54.

Kerin, R. A., Varadarajan, P. R., Peterson, R. A 1992. First-mover advantage: A synthesis, conceptual framework, and research propositions. Journal of Marketing, 56(4): 33-52.

Lawrence, P.R., and Lorsch, J.W. 1967. Organization and Environment: Managing Differentiation and

Lieberman, M. B., \& Montgomery, D. B. 1988. First-mover advantages. Strategic Management Journal, 9: 41-58.

Lieberman, M. B., \& Montgomery, D. B. 1998. First-mover (dis)advantages: Retrospective and link with the resource-based view. Strategic Management Journal, 19(12): 1111-1125.

Lieberman, M.B., 1984. The Learning Curve and Pricing in the Chemical Processing Industries. The RAND Journal of Economics, 15(2): 213-228.

Lieberman, M.B., 1989 The Learning Curve, Technology Barriers to Entry, and Competitive Survival in the Chemical Processing Industries. Strategic Management Journal. 10(5): 431-447.

Lippman, S.A., and Rumlet, R.P. 1982. Uncertain Imitability: An Analysis of Interfirm Differences in Efficiency under Competition The Bell Journal of Economics, 13(2): 418-438. Management Journal, 32: 543-576

Mitchell, W. 1989. Whether and When? Probability and Timing of Incumbents' Entry into Emerging Industrial Subfields. Administrative Science Quarterly, 34: 208-230.

Mitchell, W. 1991. Dual clocks: Entry order influences on incumbent and newcomer market share and survival when specialized assets retain their value. Strategic Management Journal, 12(2): 85-100.

Moore, G. E. 1995. Lithography and the Future of Moore's Law. Proceedings of the International Society for Optical Engineering, 2438: 2-17.

Moore, J. F. 1996. The Death of Competition : Leadership and Strategy in the Age of Business Ecosystems: Harper Business.

Morison, Elting. 1966. Men, Machines and Modern Times. Cambridge:Mass. MIT Press.

Novak, S., \& Stern, S. 2008. How Does Outsourcing Affect Performance Dynamics? Evidence from the Automobile Industry. Management Science, 54(12): 1963-1979.

Porter, M. E. 1980. Competitive Strategy: Techniques for Analyzing Industries and Competition. New York: The Free Press.

Rivkin, J. W. 2000. Imitation of Complex Strategies. Management Science, 46(6): 824-844.

Rosenberg, N. 1972. Factors Affecting the Diffusion of Technology. Explorations in Economic History, 10(1):3-33.

Rosenberg, N. 1976. On Technological Expectations. The Economic Journal, 86(343): 523-535.

SAP Corporation. 2006. "SAP Ecosystem Unites to Bring Innovation to Chemicals Industry." Press release. May 8.

Spence, M. 1981. The Learning Curve and Competition The Bell Journal of Economics. 12(1):49-70.

Stigler, G.J. 1951. The division of labor is limited by the extent of the market. Journal of Political Economy. 59(3). 
Suarez, F.F. and Lanzolla, G. 2007. The Role of Environmental Dynamics in Building a First Mover Advantage Theory. The Academy of Management Review, 32(2):377 - 392.

Teece, D. J. 1986. Profiting from Technological Innovation: Implications for Integration, collaboration, Licensing and Public Policy. Research Policy, 15(6): 285-305.

Tripsas, M. 1997. Unraveling the process of creative destruction: complementary assets and incumbent survival in the typesetter industry. Strategic Management Journal, 18(6): 119-142.

Tripsas, M. 2006. Customer Preference Discontinuities: A Trigger for Radical Technological Change. Managerial and Decision Economics

Tripsas, M., \& Gavetti, G. 2000. Capabilities, cognition, and inertia: Evidence from digital imaging. Strategic Management Journal, 21(10/11): 1147.

Tushman, M. L., \& Anderson, P. 1986. Technological discontinuities and organizational environments. Administrative Science Quarterly, 31(3): 439-465.

Tushman, M. L., \& Romanelli, E. 1985. Organisational evolution: A metamorphosis model of convergence and reorientation. Research in Organisational Behaviour, 7: 171-222.

VanderWerf, P. A., \& Mahon, J. F. 1997. Meta-Analysis of the Impact of Research Methods on Findings of FirstMover Advantage. Management Science, 43(11): 1510-1519.

Williamson, O. E. 1985. The economic institutions of capitalism: firms, markets, relational contracting. New York, London: Free Press, Collier Macmillan.

Wooldridge, J. M. 2002. Econometric Analysis of Cross Section and Panel Data. Cambridge, MA: MIT Press. 
TABLE 1: Major technological innovations by the lithography equipment ecosystem to overcome the challenges accompanying new technology generations.

\begin{tabular}{|c|c|c|c|c|c|c|}
\hline $\begin{array}{l}\text { Technology } \\
\text { Generation } \\
\text { (Year of First } \\
\text { Sale) }\end{array}$ & $\begin{array}{l}\text { Resolu } \\
\text { tion } \\
(\mu \mathrm{m})\end{array}$ & Tool & Source & Lens & Mask & Resist \\
\hline $\begin{array}{l}\text { Initial Solution } \\
\text { (pre-1962) }\end{array}$ & & & Mercury Lamp & None & Manually cut mask & Negative resist \\
\hline $\begin{array}{l}\text { Contact Printer } \\
\text { (1962) }\end{array}$ & 7.00 & $\begin{array}{l}\text { Circuit design is transferred to wafer by } \\
\text { putting mask in direct contact with the } \\
\text { resist on the wafer and then shining the } \\
\text { light energy from the mercury lamp }\end{array}$ & - & - & $\begin{array}{l}\text { Introduction of Step \& } \\
\text { Repeat Camera for } \\
\text { mask making. }\end{array}$ & - \\
\hline $\begin{array}{l}\text { Proximity Printer } \\
\text { (1972) }\end{array}$ & 3.00 & $\begin{array}{l}\text { The mask is separated from the wafer by a } \\
\text { small gap. Eliminating direct contact } \\
\text { reduces defect rates. }\end{array}$ & - & - & - & - \\
\hline $\begin{array}{l}\text { Projection } \\
\text { Scanner } \\
(1973)\end{array}$ & 2.00 & $\begin{array}{l}\text { A reflective lens system is incorporated } \\
\text { into the tool to allow for greater } \\
\text { concentration of light energy to be } \\
\text { transferred through the mask onto the }\end{array}$ & - & $\begin{array}{l}\text { Development of } \\
\text { Reflective lens } \\
\text { system. }\end{array}$ & $\begin{array}{l}\text { Use of Electron Beam } \\
\text { systems for high quality } \\
1 \mathrm{X} \text { masks }\end{array}$ & - \\
\hline $\begin{array}{l}\text { E-Beam Writer } \\
(1976)\end{array}$ & 0.5 & $\begin{array}{l}\text { Move an electron beam through a } \\
\text { preprogrammed path to create the circuit } \\
\text { pattern directly on the resist without use } \\
\text { of lens or mask. }\end{array}$ & $\begin{array}{l}\text { Development } \\
\text { of thermionic } \\
\text { and field } \\
\text { emission }\end{array}$ & - & - & $\begin{array}{l}\text { New developments with } \\
\text { PMMA based resist }\end{array}$ \\
\hline $\begin{array}{l}\text { X-Ray Printer } \\
(1978)\end{array}$ & 0.3 & $\begin{array}{l}\text { Change wavelength from } 435 \mathrm{~nm} \text { to } 10 \mathrm{~nm} \\
\text { and project energy from an } \mathrm{x} \text {-ray source } \\
\text { without use of a lens. }\end{array}$ & $\begin{array}{l}\text { Development } \\
\text { of synchrotron } \\
\text { for providing a } \\
\text { high energy }\end{array}$ & - & $\begin{array}{l}\text { Development of new } \\
\text { mask materials such as } \\
\text { SiC/Ta. }\end{array}$ & - \\
\hline $\begin{array}{l}\text { G-Line Stepper } \\
(1978)\end{array}$ & 1.25 & $\begin{array}{l}\text { Step-and-repeat technology allows a } \\
\text { single wafer to be etched through multiple } \\
\text { exposures as the mask is shifted across the } \\
\text { wafer in steps. A refractive lens system } \\
\text { allows for the circuit dimensions on the }\end{array}$ & - & $\begin{array}{l}\text { Development of } \\
\text { Refractive lens } \\
\text { system. }\end{array}$ & - & $\begin{array}{l}\text { Change in resist from } \\
\text { standard Negative resist } \\
\text { to Novolac resist to } \\
\text { provide low resolution. }\end{array}$ \\
\hline
\end{tabular}




\begin{tabular}{|c|c|c|c|c|c|c|}
\hline $\begin{array}{l}\text { I-Line Stepper } \\
(1985)\end{array}$ & 0.80 & $\begin{array}{l}\text { Wavelength derived from the mercury } \\
\text { lamp energy source is reduced from } \\
435 \mathrm{~nm} \text { to } 365 \mathrm{~nm} \text {. }\end{array}$ & - & $\begin{array}{l}\text { Development of } \\
\text { new lens material } \\
\text { for reduced } \\
\text { wavelength. }\end{array}$ & - & - \\
\hline $\begin{array}{l}\text { DUV 248nm } \\
\text { Stepper } \\
\text { (1986) }\end{array}$ & 0.45 & $\begin{array}{l}\text { Wavelength is reduced from } 365 \mathrm{~nm} \text { to } \\
248 \mathrm{~nm} \text {. }\end{array}$ & $\begin{array}{l}\text { Development } \\
\text { of Krypton } \\
\text { Fluoride }(\mathrm{KrF}) \\
\text { excimer laser. }\end{array}$ & $\begin{array}{l}\text { Change in lens } \\
\text { material to Fused } \\
\text { Silica. }\end{array}$ & $\begin{array}{l}\text { Change in mask } \\
\text { material to quartz. }\end{array}$ & $\begin{array}{l}\text { Change in resist to } \\
\text { chemically amplified } \\
\text { resist. }\end{array}$ \\
\hline $\begin{array}{l}\text { DUV 193nm } \\
\text { Stepper } \\
\text { (1996) }\end{array}$ & 0.15 & $\begin{array}{l}\text { Wavelength is reduced from } 365 \mathrm{~nm} \text { to } \\
248 \mathrm{~nm} \text {. }\end{array}$ & $\begin{array}{l}\text { Development } \\
\text { of Argon } \\
\text { Fluoride (ArF) } \\
\text { excimer laser. }\end{array}$ & $\begin{array}{l}\text { Change in lens } \\
\text { material to Calcium } \\
\text { Fluoride }\end{array}$ & $\begin{array}{l}\text { Introduction of RET } \\
\text { Masks for } 193 \mathrm{~nm} \text {. }\end{array}$ & $\begin{array}{l}\text { New versions of } \\
\text { chemically amplified } \\
\text { resist were developed } \\
\text { for } 193 \mathrm{~nm} \text { wavelength. }\end{array}$ \\
\hline
\end{tabular}


TABLE 2: Variable descriptions.

\begin{tabular}{|c|c|}
\hline Variables & Description \\
\hline \multicolumn{2}{|l|}{ Dependent Variable } \\
\hline Generation Share & Firm's market share in a given generation in a given year. \\
\hline \multicolumn{2}{|l|}{ Key Variables in Study } \\
\hline Technology Leadership & $\begin{array}{l}\text { Entry timing for the firm in the new generation. Leadership position is } \\
\text { defined as } 1 \text { for the first entrant and subsequent entry is measured with } \\
\text { respect to the lag in years from the first entry. }\end{array}$ \\
\hline Component Challenge & $\begin{array}{l}\text { Number of technical articles appearing in the industry journal no later } \\
\text { than } 5 \text { years after the emergence of the new generation that refer to lens } \\
\text { and source innovation in the given generation. }\end{array}$ \\
\hline Complement Challenge & $\begin{array}{l}\text { Number of technical articles appearing in the industry journal no later } \\
\text { than } 5 \text { years after the emergence of the new generation that refer to mask } \\
\text { and resist innovation in the given generation. }\end{array}$ \\
\hline Vertical Integration & $\begin{array}{l}\text { Dummy }=1 \text { for a firm with a separate business unit performing } \\
\text { manufacturing of lens component for the generation. }\end{array}$ \\
\hline Technology Maturity & $\begin{array}{l}\text { Count of number of years between a technology generation's year of first } \\
\text { sale and the given year. }\end{array}$ \\
\hline \multicolumn{2}{|l|}{ Control Variables } \\
\hline Incumbent & $\begin{array}{l}\text { Dummy }=1 \text { for a firm that sold lithography tools in an earlier technology } \\
\text { generation. }\end{array}$ \\
\hline Conglomerate & Dummy = 1 for a firm that was active in multiple industries. \\
\hline Generation Sales Growth & Annual sales growth rate of the generation. \\
\hline Number of Firms & Number of firms active in the generation in a given year. \\
\hline
\end{tabular}


TABLE 3: Descriptive statistics and correlations.

\begin{tabular}{|c|c|c|c|c|c|c|c|c|c|c|c|c|c|c|c|c|c|}
\hline & Variables & Mean & $\begin{array}{l}\text { Std. } \\
\text { Dev. }\end{array}$ & Min & Max & 1 & 2 & 3 & 4 & 5 & 6 & 7 & 8 & 9 & 10 & 11 & 12 \\
\hline 1 & Ln(Generation Share) & -1.83 & 1.26 & -6.21 & 0.00 & & & & & & & & & & & & \\
\hline 2 & Technology Leadership*Component Challenge & -0.64 & 7.69 & -30.18 & 22.91 & -0.05 & & & & & & & & & & & \\
\hline 3 & Technology Leadership*Complement Challenge & 1.90 & 8.79 & -22.47 & 32.71 & 0.24 & -0.20 & & & & & & & & & & \\
\hline 4 & Vertical integration*Technology Maturity & 2.66 & 5.63 & 0.00 & 27.00 & 0.23 & 0.10 & -0.02 & & & & & & & & & \\
\hline 5 & Technology Leadership ${ }^{a}$ & 3.55 & 2.93 & 1.00 & 13.00 & -0.35 & -0.34 & 0.24 & -0.07 & & & & & & & & \\
\hline 6 & Component Challenge $^{\mathrm{a}}$ & 3.57 & 2.44 & 0.00 & 8.00 & -0.03 & -0.01 & -0.36 & 0.09 & -0.09 & & & & & & & \\
\hline 7 & Complement Challenge $^{\mathrm{a}}$ & 4.13 & 2.67 & 0.00 & 10.00 & 0.13 & -0.38 & 0.09 & -0.15 & 0.24 & 0.32 & & & & & & \\
\hline 8 & Vertical Integration & 0.23 & 0.42 & 0.00 & 1.00 & 0.22 & 0.10 & -0.03 & 0.85 & -0.12 & 0.15 & -0.13 & & & & & \\
\hline 9 & Incumbent & 0.48 & 0.50 & 0.00 & 1.00 & -0.05 & 0.03 & -0.26 & 0.28 & 0.15 & 0.39 & 0.06 & 0.31 & & & & \\
\hline 10 & Conglomerate & 0.49 & 0.50 & 0.00 & 1.00 & 0.23 & 0.07 & -0.08 & 0.48 & -0.34 & 0.23 & -0.10 & 0.56 & 0.21 & & & \\
\hline 11 & Generation Sales Growth & 40.78 & 106.11 & -76.02 & 874.05 & -0.07 & 0.06 & -0.03 & -0.08 & -0.09 & 0.12 & 0.06 & 0.04 & 0.10 & 0.03 & & \\
\hline 12 & Number of Firms & 4.92 & 2.38 & 1.00 & 11.00 & -0.45 & 0.07 & -0.19 & -0.03 & -0.03 & 0.06 & -0.17 & 0.00 & -0.09 & 0.06 & 0.10 & \\
\hline 13 & Technology Maturity & 11.26 & 6.68 & 1.00 & 32.00 & 0.16 & -0.10 & 0.18 & 0.23 & 0.22 & -0.15 & -0.12 & 0.01 & -0.11 & -0.01 & -0.33 & -0.24 \\
\hline
\end{tabular}

$\mathrm{N}=676$, Correlations greater than 0.08 are significant at $\mathrm{p}<0.05$

${ }^{a}$ Variable is mean-centered (mean, min and max are shown for the pre-centered values) 
TABLE 4: Coefficient estimates from panel regression. Dependent Variable $=\mathbf{L n}($ Generation Share $)$

\begin{tabular}{|c|c|c|c|c|c|c|}
\hline & Model 1 & Model 2 & Model 3 & Model 4 & Model 5 & Model $6^{\mathrm{a}}$ \\
\hline \multirow[t]{2}{*}{ Technology Leadership*Component Challenge } & & $-0.040 * * *$ & & & $-0.042 * * *$ & $-0.044 * * *$ \\
\hline & & $(0.009)$ & & & $(0.009)$ & $(0.013)$ \\
\hline \multirow[t]{2}{*}{ Technology Leadership*Complement Challenge } & & & $0.022 * *$ & & $0.020 * *$ & $0.020 *$ \\
\hline & & & $(0.009)$ & & $(0.008)$ & $(0.011)$ \\
\hline \multirow[t]{2}{*}{ Vertical integration*Technology Maturity } & & & & $0.034 * *$ & $0.041 * * *$ & $0.029 *$ \\
\hline & & & & $(0.016)$ & $(0.016)$ & $(0.017)$ \\
\hline \multirow[t]{2}{*}{ Technology Leadership } & $-0.146 * * *$ & $-0.148 * * *$ & $-0.163 * * *$ & $-0.142 * * *$ & $-0.158 * * *$ & $-0.156 * * *$ \\
\hline & $(0.022)$ & $(0.019)$ & $(0.020)$ & $(0.022)$ & $(0.018)$ & $(0.024)$ \\
\hline \multirow[t]{2}{*}{ Vertical integration } & $0.406^{* * *}$ & 0.245 & $0.398 * *$ & 0.047 & -0.205 & 0.012 \\
\hline & $(0.156)$ & $(0.151)$ & $(0.156)$ & $(0.231)$ & $(0.227)$ & $(0.281)$ \\
\hline \multirow[t]{2}{*}{ Component Challenge } & -0.036 & -0.045 & -0.001 & -0.052 & -0.033 & -0.035 \\
\hline & $(0.047)$ & $(0.044)$ & $(0.048)$ & $(0.049)$ & $(0.047)$ & $(0.115)$ \\
\hline \multirow[t]{2}{*}{ Complement Challenge } & $0.102 * * *$ & $0.074 * * *$ & $0.086 * * *$ & $0.104 * * *$ & $0.061 * * *$ & 0.028 \\
\hline & $(0.025)$ & $(0.022)$ & $(0.024)$ & $(0.025)$ & $(0.023)$ & $(0.031)$ \\
\hline \multirow[t]{2}{*}{ Technology Maturity } & 0.003 & -0.025 & 0.014 & -0.011 & -0.033 & -0.029 \\
\hline & $(0.017)$ & $(0.018)$ & $(0.017)$ & $(0.019)$ & $(0.020)$ & $(0.040)$ \\
\hline \multirow[t]{2}{*}{ Incumbent } & $-0.609 * * *$ & $-0.757 * * *$ & $-0.423 * * *$ & $-0.658 * * *$ & $-0.655 * * *$ & $-0.769 * * *$ \\
\hline & $(0.124)$ & $(0.127)$ & $(0.144)$ & $(0.127)$ & $(0.151)$ & $(0.253)$ \\
\hline \multirow[t]{2}{*}{ Conglomerate } & 0.875 & -0.215 & 0.397 & $2.845 * * *$ & $2.697 * * *$ & $2.812 * * *$ \\
\hline & $(0.585)$ & $(0.579)$ & $(0.541)$ & $(0.310)$ & $(0.355)$ & $(0.447)$ \\
\hline \multirow[t]{2}{*}{ Generation Sales Growth } & -0.000 & -0.001 & -0.000 & -0.000 & -0.001 & -0.000 \\
\hline & $(0.000)$ & $(0.000)$ & $(0.000)$ & $(0.000)$ & $(0.000)$ & $(0.000)$ \\
\hline \multirow[t]{2}{*}{ Number of Firms } & $-0.183 * * *$ & $-0.181 * * *$ & $-0.179 * * *$ & $-0.189 * * *$ & $-0.184 * * *$ & $-0.178 * * *$ \\
\hline & $(0.020)$ & $(0.020)$ & $(0.020)$ & $(0.020)$ & $(0.020)$ & $(0.024)$ \\
\hline \multirow[t]{2}{*}{ Constant } & -1.066 & 0.194 & -1.393 & $-3.190 * * *$ & $-2.407 * * *$ & $-2.401 * *$ \\
\hline & $(0.867)$ & $(0.951)$ & $(0.860)$ & $(0.613)$ & $(0.655)$ & $(1.126)$ \\
\hline Firm Dummies & Included & Included & Included & Included & Included & Included \\
\hline Year Dummies & Included & Included & Included & Included & Included & Included \\
\hline $\mathrm{R}^{2}$ - within & 0.17 & 0.17 & 0.17 & 0.19 & 0.19 & 0.19 \\
\hline $\mathrm{R}^{2}$ - between & 0.77 & 0.83 & 0.78 & 0.77 & 0.83 & 0.83 \\
\hline $\mathrm{R}^{2}$ - overall & 0.58 & 0.61 & 0.60 & 0.59 & 0.62 & 0.62 \\
\hline Observations & 676 & 676 & 676 & 676 & 676 & 521 \\
\hline
\end{tabular}

Robust standard errors in parentheses clustered for intra-panel correlation, * significant at $10 \%$; ** significant at $5 \%$; *** significant at $1 \%$

${ }^{a}$ Model 6 excludes observations from X-ray and E-beam generations. 
Figure 1: Generic Schema of an Ecosystem.

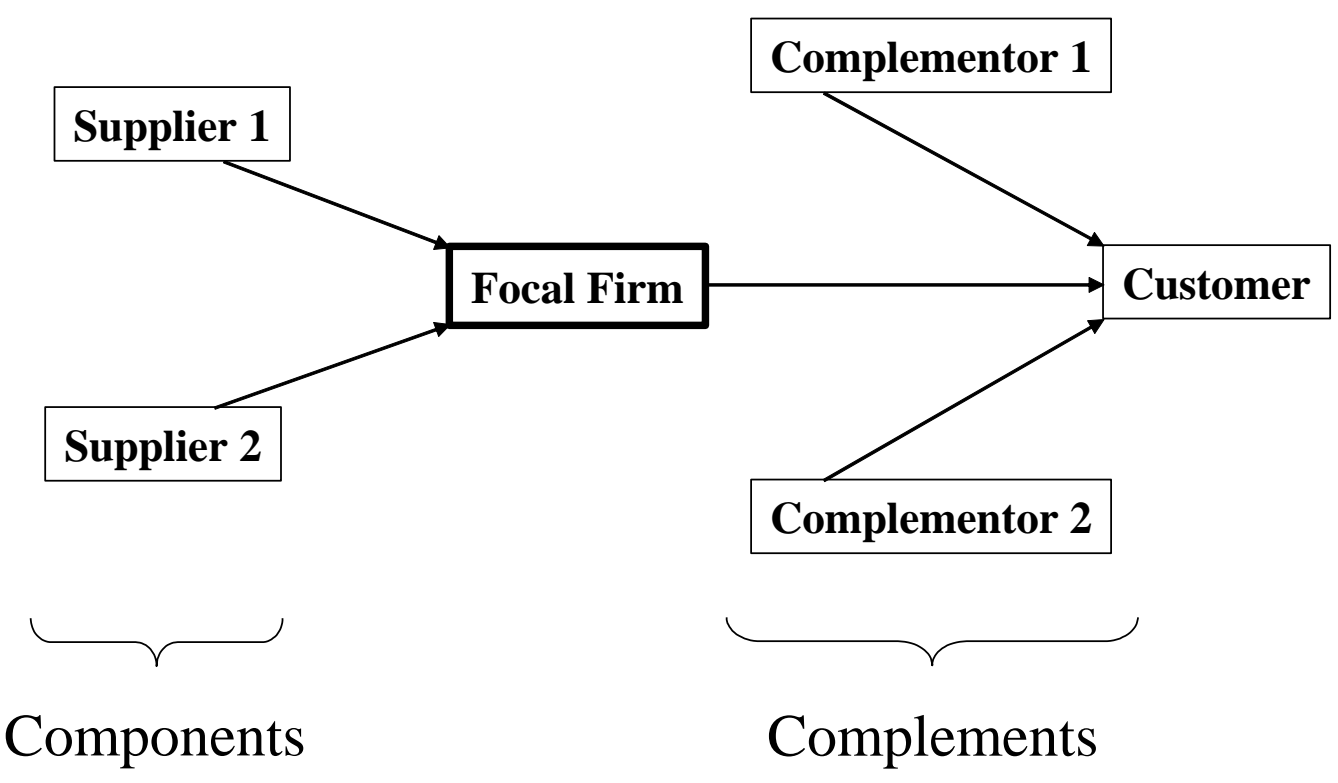

Figure 2: Basic Schema of the Semiconductor Lithography Process.

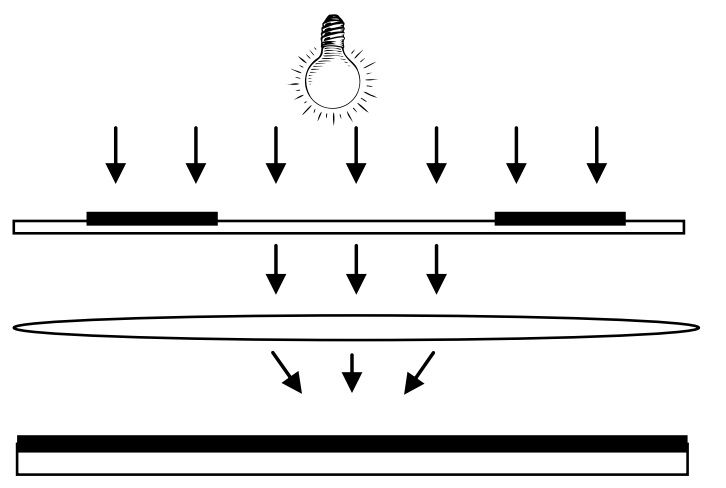

Energy Source

Mask with IC pattern on Top

Lens

Semiconductor Wafer with Resist Layer 
Figure 3: The Semiconductor Lithography Equipment Ecosystem.

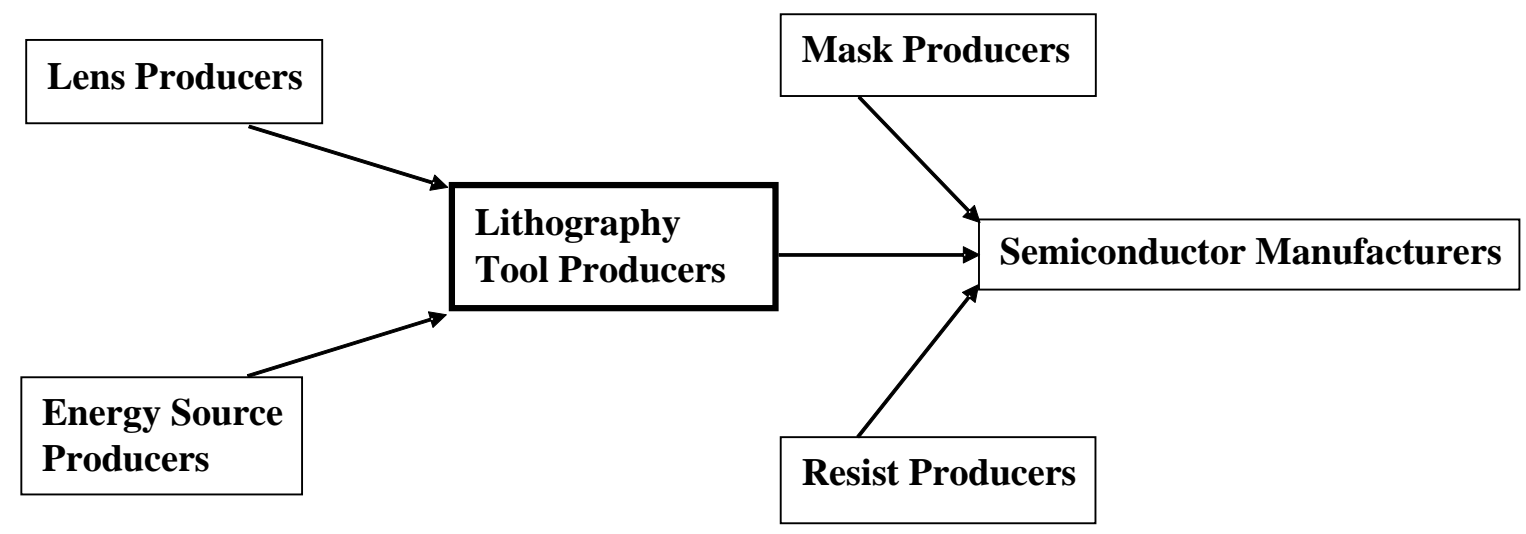

Figure 4: Distribution of challenges among ecosystem elements in nine semiconductor lithography equipment generations.

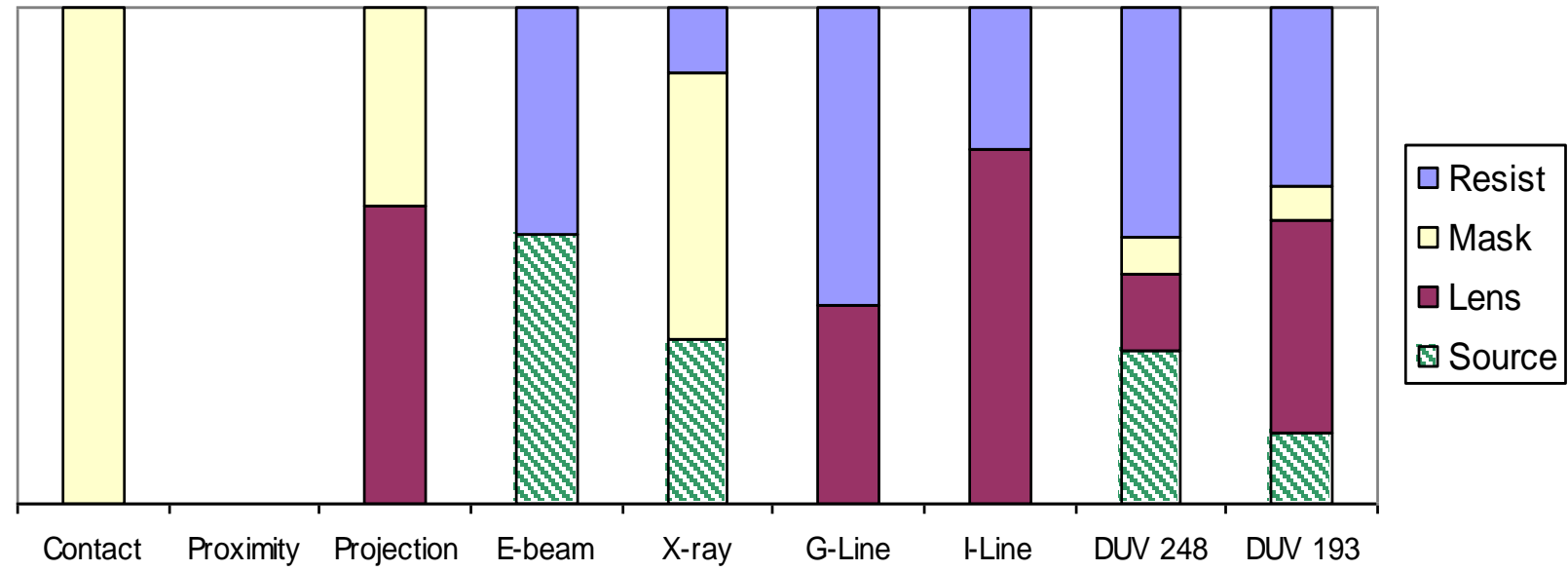


Figure 5: Difference in expected market share between a technology leader and a follower as a function of ecosystem challenge and the follower's entry timing.

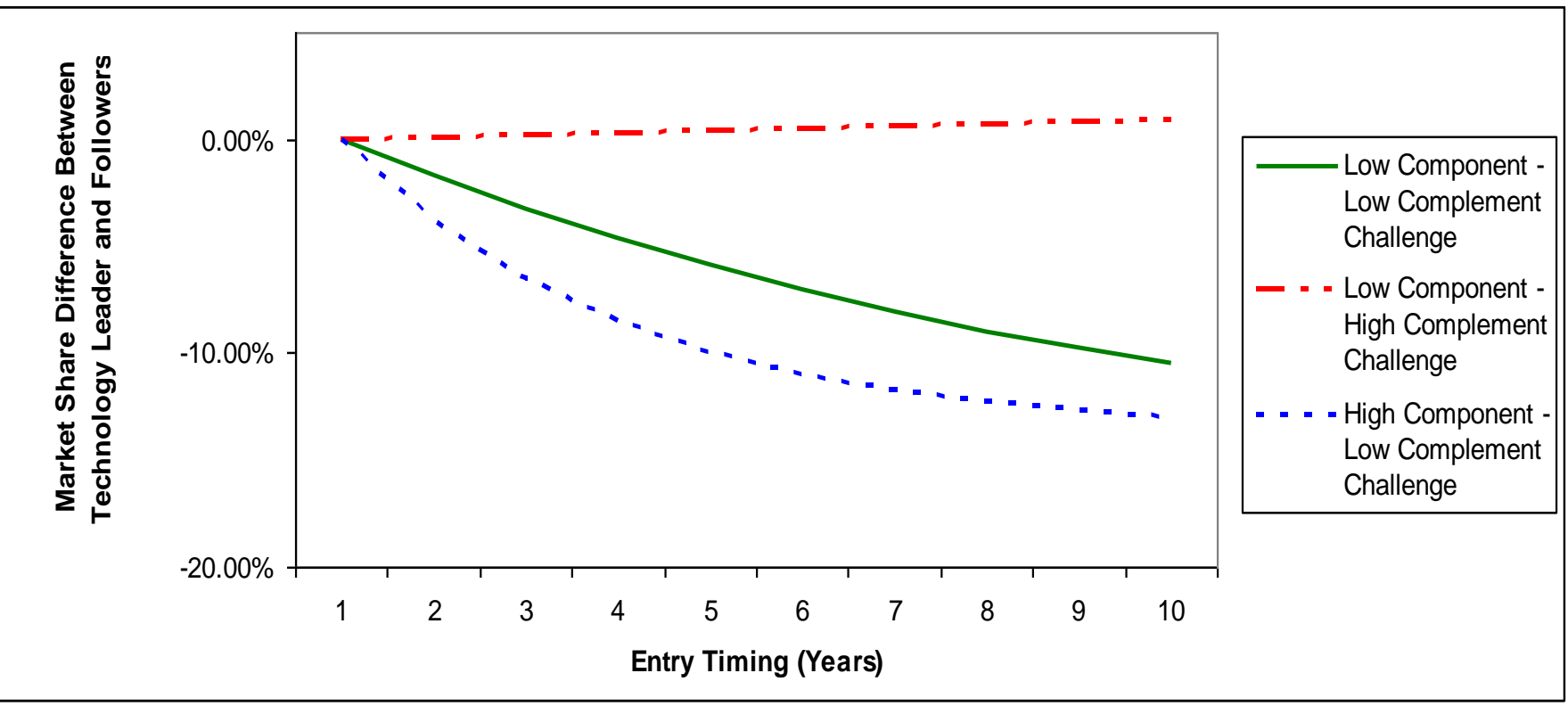




\section{Appendix I: Technology Transitions in the Semiconductor Lithography Equipment Industry from 1962 to 2005}

This discussion is based on the industry history presented in Kapoor and Adner (2007).

Optical Technologies

Optical lithography technologies use light of different wavelengths to create patterns on the

semiconductor substrate. These technologies have been dominant in the industry despite repeated expectations for their substitution (see Henderson, 1995 for an intriguing discussion).

Contact Printers - Contact printing was the earliest and the simplest of the lithography technologies to be commercialized. The modifier 'contact' corresponds to the fact that the mask and the semiconductor wafer were in direct contact with each other. The contact printers in the 1960's included a stage system for securing the mask and the wafer, and an alignment unit that ensured that the patterns from the mask were accurately transferred to the wafer. They used a mercury lamp for their energy source, an existing component already used in movie projectors of the time. Contact printers did not incorporate a lens. The resist used by semiconductor firms as a complement to the tool, known as negative resist, was readily available and already being used by Kodak in photography applications.

The main ecosystem challenge to the emergence of commercial contact printers stemmed from difficulties in the manufacture of suitable masks. Masks were made using a three stage process. First the desired circuit pattern was cut from a plastic laminate. This cutting was done using a manually operated tool which could achieve an accuracy of approximately $100 \mu \mathrm{m}(0.1 \mathrm{~mm})$. Second, the circuit image was etched on to an emulsion plate which became the 'master' mask. Finally, the master mask was used to create copies of itself which served as 'production' masks.

This early mask making process presented two inherent limitations. First, the resolution of the manually cut masks acted to limit the performance achievable by the contact printers. Second, the master mask was highly susceptible to wear during the production mask making process, which led to high manufacturing defects and hence reduced productivity.

To address these challenges, the mask making industry introduced two new innovations during the 1960's. The first was the computerization and automation of the mask making process using high-speed step and repeat cameras. The second was the introduction of master masks made of chrome patterned glass that could be cleaned and reused several times, reducing the defects in the production masks.

Proximity Printers - A primary disadvantage of contact printing was low process yield. This was due to the damage inflicted on the mask and the wafers as they were repeatedly brought in and out of physical contact with each other during the lithography process. Proximity printing, introduced in 1972, offered a way to overcome this problem. With proximity printing the mask and the wafer were separated by a tiny gap in order to reduce the defects that had been caused by their direct contact. This reconfiguration allowed for significant enhancement in resolution, achieving geometries of $3 \mu \mathrm{m}$. As discussed in detail by Henderson and Clark (1990), this generational transition can be characterized as an architectural innovation and imposed significant innovation challenges on the focal lithography equipment firms. The transition to proximity printing did not, however, present major innovation challenges to any other actors in the lithography ecosystem.

Projection Scanners - The continuous need of semiconductor manufacturers to reduce circuit dimensions and get better manufacturing yields led to the introduction of another architectural innovation in 1974. Projection scanners introduced the use of lens systems as a component in lithography tools. The lens system was composed of a series of reflective mirrors which allowed the image of the mask to be transferred to the wafer. Projection scanners allowed for resolution as low as $2 \mu \mathrm{m}$. The ecosystem challenges during the development and emergence of this generation were in the lens system, a new component that was developed specifically for the lithography industry; and in the mask, which needed to be etched with correspondingly smaller geometries and greater accuracy. To meet the mask manufacturing challenge, mask makers switched from using step and repeat cameras to using electron beam systems in their production process.

G-line Steppers - Step-and-repeat (stepper) technology was introduced in 1978. The G-line stepper, an architectural innovation, introduced two key modifications. First, light was projected through the mask on to the wafer using a refractive lens system (as opposed to the reflective lens system used in projection scanners). Second, the light was projected on only a part of the wafer at any one time; the mask was shifted across the wafer in steps, such that multiple exposures are made across the wafer to complete the lithography process. G-line steppers operated at a wavelength of 435 nanometer $(\mathrm{nm})$ and allowed users to achieve resolution as low as $1.25 \mu \mathrm{m}$. The 
transition to G-line steppers imposed significant challenges on the ecosystem. In terms of components, it required the development of a refractive lens comprised of several precise glass elements that would minimize distortion and transmit light accurately on to the wafer. In terms of complements, the transition to G-line steppers required the development of a resist that would allow for sufficiently small geometries; that is, a resist in which exposure to light energy would trigger a chemical reaction only in the molecules that were directly exposed to the light, without setting off a reaction in adjacent molecules. The negative resist, which had been used to this point in the industry's evolution, was inadequate to the task. The resist challenge was resolved through the development of new novolac-based materials.

I-line Steppers-I-line steppers, introduced in 1985, used light with a wavelength of $365 \mathrm{~nm}$ to improve over the resolution achievable with the G-line generation. ${ }^{15}$ The main ecosystem challenge was to develop a lens that would transmit light at the lower wavelength. This required the development of a new glass material and corresponding changes to the lens production process. The remaining ecosystem elements required only incremental changes for the transition from the G-line generation. I-line steppers allowed for resolutions as low as $0.8 \mu \mathrm{m}$.

DUV 248nm Steppers - The next step in the industry's technology evolution was the introduction of DUV $248 \mathrm{~nm}$ steppers in 1988. This generation entailed a further reduction in wavelength into the deep ultraviolet (DUV) spectrum at $248 \mathrm{~nm}$. The reduction in wavelength required fundamental changes in the energy source, the lens, the mask, and the resist.

Mercury lamps, which had been used in all earlier generations, were not able to provide sufficient energy at a wavelength of $248 \mathrm{~nm}$ to cause adequate chemical reactions in the resist. This challenge was overcome by the development of excimer lasers using Krypton Fluoride (KrF) gas. The conventional glass material that was used to make lenses faced absorption problems with $248 \mathrm{~nm}$ wavelength. The only material that could be used was fused silica, and this required major changes to the lens manufacturing process. The challenges imposed on mask makers were overcome by changing the mask material from soda lime glass to quartz in order to provide improved transmission of the $248 \mathrm{~nm}$ wavelength. This, in turn, required major changes to the mask manufacturing process. Finally, the existing novolac resists could not absorb enough energy from the new wavelength to cause an adequate chemical reaction. As a result, new chemically-amplified resist had to be developed for semiconductor manufacturers to create fine circuits using the new lithography technology. After the ecosystem challenges were overcome, DUV $248 \mathrm{~nm}$ steppers could provide resolutions as low as $0.45 \mu \mathrm{m} .{ }^{16}$

DUV 193nm Steppers - The industry's drive towards finer resolutions continued when tools using the DUV 193nm wavelength were introduced in 1996. As was the case for the DUV 248, the very low light wavelength created new challenges in every part of the ecosystem. Since KrF lasers could not produce light with wavelength of $193 \mathrm{~nm}$, a new excimer laser that used Argon Fluoride (ArF) gas was developed. New challenges were also posed by light absorption problems with the existing lens materials. The challenges were overcome with the development of a new lens material, calcium fluoride. The resist and the mask also had to undergo major developments so that this new generation could create value for users. With the change to the $193 \mathrm{~nm}$ wavelength, the existing resists, which were engineered to react to the $248 \mathrm{~nm}$ wavelength, were no longer adequate to the task - a new generation of chemically amplified resist needed to be developed. Finally, resolution enhancement

${ }^{15}$ The resolution capability of lithography technologies that employ a lens system is given by the Rayleigh criterion:

Resolution $=k_{1} x($ Wavelength/Numerical Aperture $)$

where wavelength is the wavelength of the light being transmitted by the source, numerical aperture is the measure of the size of the lens, and $\mathrm{k}_{1}$ is a process-specific constant. Hence, to improve the resolution of lithography tools, manufacturers can either reduce the wavelength of light or increase the size of the lens. A key source of improvement within the course of a given technology generation has been increases in lens size. When further increases in lens size become untenable, due to a combination of physical and economic constraints on production, the industry shifts to a new, smaller, wavelength which heralds the emergence of a new technology generation.

${ }^{16}$ Firms that entered the DUV $248 \mathrm{~nm}$ generation employed two different architectures. With the exception of Silicon Valley Group, all firms initially developed step-and-repeat systems for the DUV 248nm generation. Silicon Valley Group entered the new generation with a new step-and-scan architecture (the original step-and-scan technology was developed by Perkin Elmer, which was acquired by Silicon Valley Group). Step-and-scan systems, an architectural innovation, can be considered a hybrid between projection scanners and step-and-repeat steppers. The main benefit was a significant reduction in lens complexity that would provide lower resolution and a larger field size in order to satisfy the growing demand of large size logic IC's. Most firms producing DUV 248nm step and repeat systems eventually moved to the step-and-scan architecture during the course of the generation. 
technologies (RETs) needed to be developed in order to create masks that could exploit the finer resolution available from the DUV $193 \mathrm{~nm}$ steppers. ${ }^{17}$ Once these challenges were overcome, DUV $193 \mathrm{~nm}$ steppers were able to provide resolutions of $0.15 \mu \mathrm{m}$.

\section{Non-Optical Technologies}

Since the early 1960 's, optical lithography has been the mainstay of semiconductor manufacturing. However, there have been several attempts to introduce non-optical technologies that would offer smaller geometries by using much smaller energy wavelengths outside of the visible spectrum.. Amongst these, the two technologies that attracted the most interest, resources, and market share were X-ray and electron-beam (E-beam) lithography. ${ }^{18}$

$X$-ray Printers - The use of X-rays for lithography was proposed due to their very low wavelength of less than $10 \mathrm{~nm}$. In the early 1970 's, X-ray lithography was developed as a simple proximity imaging system. As in proximity printing, the radiation from an X-ray source is transmitted through the mask onto the resist. X-ray lithography's very low wavelength created substantial challenges to the implementation of the technology for semiconductor manufacturing. These challenges included major changes to the source and the mask. Although it was first introduced in 1978 with great fan fare, X-ray printing has never entered the mainstream - as of the time of this writing, its ecosystem challenges have yet to be overcome at a competitive, commercial scale.

E-Beam Writers - Electron-beam (E-beam) technology involves patterning the resist on the semiconductor wafer directly using electron beams the follow a pre-programmed pattern, thereby eliminating the need for a mask. The major concern with this technology has been its throughput. Since a pre-programmed electron beam travels across the wafer to achieve very low resolution, the time required to complete a single wafer can be as high as $10 \mathrm{hrs,} \mathrm{which} \mathrm{is} \mathrm{almost} \mathrm{an} \mathrm{order} \mathrm{of} \mathrm{magnitude} \mathrm{longer} \mathrm{than} \mathrm{the} \mathrm{alternate} \mathrm{optical} \mathrm{lithography}$ technologies. This throughput disadvantage has relegated E-beam writers to high-end, low volume niches. The major ecosystem challenges posed by E-beam technology are the development of the E-beam source to increase throughput, as well as new resist chemistries that work with the emitted electrons. At first glance, it might seem that E-beam lithography should be characterized as a radical technological change for producers. In fact, however, every firm that entered with an E-beam tool had already offered E-beam based products to other markets (e.g., electron microscopy). For these firms, E-beam writers for semiconductor lithography presented only incremental innovation challenges. None of the pure optical firms, for whom E-beam would have represented a genuinely radical departure, ever entered the market.

\footnotetext{
${ }^{17}$ RETs control and manipulate the light waves through the mask and the lens, and provide improved contrast of the projected circuit image. This "wavefront engineering" reduces the $\mathrm{k}_{1}$ of the Rayleigh's criterion to provide lower resolution.

${ }^{18}$ Two additional approaches, ion-beam lithography and e-beam projection lithography have also been experimented with, but neither has ever been commercialized.
} 


\section{Appendix II}

Test of Hypotheses 1 and 2 using OLS regression.

Dependent variable $=\mathrm{Ln}$ (firm's cumulative market share in a given technology generation).

\begin{tabular}{|l|l|l|l|l|l|}
\hline & Model 7 & Model 8 & Model 9 & Model 10 & Model 11 $^{\mathbf{a}}$ \\
\hline Technology Leadership*Component Challenge & & $-0.044^{*}$ & & $-0.049^{* *}$ & $-0.049^{* *}$ \\
\hline Technology Leadership*Complement Challenge & & $(0.023)$ & & $(0.019)$ & $(0.021)$ \\
\hline & & & $0.048^{*}$ & $0.052^{* *}$ & $0.053^{*}$ \\
\hline Technology Leadership & & & $(0.027)$ & $(0.025)$ & $(0.027)$ \\
\hline & -0.125 & $-0.153^{* *}$ & -0.136 & $-0.168^{* *}$ & $-0.155^{*}$ \\
\hline Component Challenge & $(0.081)$ & $(0.067)$ & $(0.083)$ & $(0.075)$ & $(0.089)$ \\
\hline & -0.107 & -0.107 & -0.074 & -0.072 & -0.099 \\
\hline Complement Challenge & $(0.106)$ & $(0.105)$ & $(0.104)$ & $(0.102)$ & $(0.149)$ \\
\hline & $0.259^{* * *}$ & $0.239^{* * *}$ & $0.245^{* * *}$ & $0.220^{* * *}$ & 0.161 \\
\hline Vertical integration & $(0.084)$ & $(0.073)$ & $(0.082)$ & $(0.072)$ & $(0.110)$ \\
\hline & $1.553^{* * *}$ & $1.681^{* * *}$ & $1.439^{* * *}$ & $1.574 * * *$ & $1.878^{* * *}$ \\
\hline Incumbent & $(0.269)$ & $(0.274)$ & $(0.277)$ & $(0.286)$ & $(0.409)$ \\
\hline & -0.483 & -0.502 & -0.403 & -0.419 & -0.406 \\
\hline Conglomerate & $(0.689)$ & $(0.636)$ & $(0.766)$ & $(0.707)$ & $(1.029)$ \\
\hline & $1.474 * *$ & $1.368^{* *}$ & $1.370^{*}$ & $1.242^{*}$ & 1.111 \\
\hline Constant & $(0.648)$ & $(0.659)$ & $(0.683)$ & $(0.694)$ & $(0.950)$ \\
\hline & $-3.821^{* * *}$ & $-3.818^{* * *}$ & $-3.834^{* * *}$ & $-3.832^{* * *}$ & $-4.010^{* * *}$ \\
\hline R-squared & $(0.393)$ & $(0.396)$ & $(0.361)$ & $(0.365)$ & $(0.589)$ \\
\hline Observations & 0.36 & 0.39 & 0.40 & 0.43 & 0.43 \\
\hline
\end{tabular}

Standard errors in parentheses, clustered by firm, * significant at 10\%; ** significant at 5\%; *** significant at $1 \%$

${ }^{a}$ Model 11 excludes observations from X-ray and E-beam generations. 